\title{
Targeted campaign competition, loyal voters, and supermajorities*
}

\author{
Pierre C. Boyer; Kai A. Konradł Brian Roberson ${ }^{\S}$
}

March 14, 2017

${ }^{*}$ We are grateful to the editor Sven Rady and the anonymous referees for their comments and suggestions. We thank Benoît Crutzen, Philipp Denter, Sergiu Hart, Daniel Kovenock, Stephan Lauermann, Debraj Ray, Dana Sisak, and Galina Zudenkova for very helpful discussions, as well as seminar participants at Mannheim University and participants at the Workshop on Contest Theory and Political Competition in Munich (2014), Workshop on electoral competition at NUI Maynooth University (2014), 20th Internal Conference of the SFB TR 15 in Bonn (2015), Erasmus Political Economy Workshop in Rotterdam (2015), conference on Advances on the Political Economy of Conflict and Redistribution III in Berlin (2015), EEA in Mannheim (2015), and Journées Louis-André Gérard-Varet in Aix-en-Provence (2016). The first author gratefully acknowledges the Max Planck Institute in Munich for hospitality and financial support, and the Investissements d'Avenir (ANR-11-IDEX-0003/Labex Ecodec/ANR-11LABX-0047) for financial support. The usual disclaimer applies.

${ }^{\dagger}$ CREST, École Polytechnique, Université Paris-Saclay, Route de Saclay, 91128 Palaiseau, France. E-mail: pierre.boyer@polytechnique.edu (corresponding author)

${ }^{\ddagger}$ Max Planck Institute for Tax Law and Public Finance, 80539 Munich, Germany. E-mail: kai.konrad@tax.mpg.de

§Purdue University, Department of Economics, Krannert School of Management, 403 W. State Street, West Lafayette, IN 47907 USA. E-mail: brobers@purdue.edu 


\begin{abstract}
We consider campaign competition in which candidates compete for votes among a continuum of voters by engaging in persuasive efforts that are targetable. Each individual voter is persuaded by campaign effort and votes for the candidate who targets more persuasive effort to this voter. Each candidate chooses a level of total campaign effort and allocates their effort among the set of voters. We completely characterize equilibrium for the majoritarian objective game and compare that to the vote-share maximizing game. If the candidates are symmetric ex ante, both types of electoral competition dissipate the rents from office in expectation. However, the equilibria arising under the two electoral objectives qualitatively differ. In majoritarian elections, candidates randomize over their level of total campaign effort, which provides support for the puzzling phenomenon of the emergence of supermajorities in majoritarian systems. Vote-share maximization leads to an equilibrium in which both candidates make deterministic budget choices and reach a precise fifty-fifty split of vote shares. We also study how asymmetry between the candidates affects the equilibrium. If some share of the voters is loyal to one of the candidates, then both candidates expend the same expected efforts in equilibrium, but the advantaged candidate wins with higher probability for majoritarian voting or a higher share of voters for vote-share maximization.
\end{abstract}

Keywords: Campaign competition; continuous General Lotto game; vote buying; flexible budgets; supermajorities, loyal voters.

JEL Classification Codes: D72; D78; D82.

\title{
1 Introduction
}

Campaign spending is an important aspect of electoral competition 11 Recent years have seen a change of paradigm with the introduction of new technologies that allow for largescale micro-targeting of campaign activities: candidates increasingly target their campaign effort towards individual voters with individualized messages instead of addressing the whole electorate, or even large groups of voters $2^{2}$ This paper presents a formal anal-

\footnotetext{
${ }^{1}$ The amount of money being spent in electoral campaigns is sizeable, and seemingly increasing. For instance, Barack Obama and Mitt Romney spent $\$ 985.7 \mathrm{~m}$ and $\$ 992.0 \mathrm{~m}$, respectively, in 2012 (see http://elections.nytimes.com/2012/campaign-finance, as viewed on May 27, 2014). As Meirowitz (2008) points out, precise policy statements play a minor role in this type of persuasive campaign spending.

${ }^{2}$ The increasing availability and usage of micro-targeting in US presidential elections was highlighted in a feature story of the MIT Technology Review in 2012 (see http://www.technologyreview.com/featuredstory/509026/how-obamas-team-used-big-data-to-rallyvoters, as viewed on July 21, 2014), as well as in Kenski, Hardy and Jamieson (2010) and Ridout, Franz, Goldstein, and Feltus (2012). See also Jamieson (2013), who envisions a change in electoral competition from a focus on swing states to swing individuals, and Hersh and Schaffner (2013).
} 
ysis that examines the implications that this change of paradigm will have on electoral competition in a modern democracy.

We consider persuasive campaign competition in majoritarian elections with two candidates and a continuum of, ex-ante homogenous, voters and compare that with a proportional, or vote-share maximizing, system in which each party's representation in a legislature is proportional to the share of votes received by that party. We assume that candidates (or parties) may anonymously target campaign spending at individual voters by employing a (general, non-decreasing) distribution of costly campaign spending. Each voter observes each candidate's voter-specific campaign effort provided to them and, then, votes for the candidate that provides them with the higher level of persuasive campaign effort.

In this setting, we show that there exists a unique Nash equilibrium and find that the problem of constructing a best-response can be decomposed into two distinct components: a budget choice problem and a budget allocation problem. Our model of campaign competition in which targeted spending is a sunk cost, provides a non-constant-sum extension of Myerson's (1993) constant-sum model of political competition. In the standard zero-sum formulation of the game, the majoritarian and vote-share maximizing objective games share the same unique equilibrium which features micro-targeting, i.e., candidates have an incentive to "cultivate favored minorities": some voters are the subject of much campaign effort, others receive very little. In our model with endogenous campaign spending, the equilibria arising in the games under each of the two objectives qualitatively differ. We find that the discontinuity in the definition of winning in a majoritarian system creates an incentive for candidates to increase the level of uncertainty in the way that they allocate campaign spending.

Because in a majoritarian system each politician's payoff has a sharp discontinuity at $50 \%$ of the votes, candidates have incentive to target the smallest possible majorities. However, as noted by Groseclose and Snyder (1996), supermajorities are frequently observed in majoritarian systems ${ }^{3}$ We find that in the unique simultaneous-move equilibrium supermajorities arise with certainty. Because the unique equilibrium features non-degenerate mixed strategies, supermajorities arise from the uncoordinated choices with regards to the sizes of the budgets chosen by the candidates, and unequal budgets translate into unequal vote shares. Hence, the analysis offers a new explanation for the emergence of supermajorities as an electoral outcome in majoritarian systems.

Our analysis can also be extended to deal with the case that each voter's evaluation of a candidate may depend upon the combination of the candidate's targeted campaign

\footnotetext{
${ }^{3}$ Iaryczower and Mattozzi (2013) discuss the importance of this discontinuity for electoral competition in majoritarian systems and compare it with proportional systems.
} 
spending and the candidate's identity. We introduce this possibility in our framework by allowing voters to either be of the loyal, or partisan, type - in which case they are loyal to a single candidate and vote for that candidate regardless of the candidates' targeted campaigning - or of the swing type - in which case the voter votes for the candidate that targets them with the higher level of campaign effort, regardless of that candidate's identity. We consider the case of coarse information in which candidates know the aggregate share of loyal voters but do not know whether any specific voter is a loyal voter or a swing voter, and of perfect information in which candidates know each individual voter's type. In comparing the possible combinations of an electoral system, majoritarian or proportional, and an information level, coarse or perfect, we find that, holding constant the electoral system, the level of information has no effect on the equilibrium expected expenditures. Because the majoritarian system generates a larger discouragement effect for the disadvantaged candidate, equilibrium expected expenditures are higher in the proportional system than in the majoritarian system, and, as a result, the advantaged candidate has a higher equilibrium expected payoff in a majoritarian system than in a proportional system, regardless of the information structure.

We proceed as follows. The next section reviews the related literature. Section 3 describes the formal framework. Section 4 solves for the Nash equilibrium. Section 5 extends our model to examine the role of private information and loyalty in political campaigns. The last section contains concluding remarks. We relegate all proofs to the Appendix.

\section{Related literature}

Within the literatures on electoral competition and multi-dimensional strategic resource allocation, our paper is most closely related to three specific strands of the literature: (i) models of redistributive politics that feature a variation of the Colonel Blotto game, (ii) models of campaign spending that feature the all-pay auction (henceforth APA), and (iii) non-constant-sum versions of the Colonel Blotto/General Lotto games and multidimensional APAs. First, our contribution is related to the literature that models redistributive politics as a variation of the Colonel Blotto game $4^{4}$ known as the General Lotto game. 5 A seminal contribution in this literature is Myerson (1993), in which candidates simultaneously choose binding promises of how they will allocate an exogenous budget

\footnotetext{
${ }^{4}$ For early contributions to this literature see Gross and Wagner (1950) and Shubik (1970). Recent contributions include Roberson (2006), Hart (2008), Kovenock and Roberson (2008), Barelli, Govindan and Wilson (2014), and Magnani (2015). For a survey see Kovenock and Roberson (2012).

${ }^{5}$ Note that in the General Lotto game budgets are satisfied on average, instead of holding with certainty as in the Colonel Blotto game.
} 
across a homogeneous electorate in the event that they win the election. Candidates may target individual voters by employing an (anonymous) distribution of transfer offers ${ }^{6}$ Each voter makes an independent draw from each candidate's effort distribution and votes for the candidate that makes the higher offer to that voter. The expected transfer from each candidate's offer distribution satisfies the budget in expectation, and the exogenous budget is the amount of tax revenue or surplus that can be distributed among the voters after the election. Myerson's and our problem have in common that each candidate wins if he attracts a majority of a continuum of voters. In his framework a voter casts his vote for the candidate who promises him a higher payment. In our framework voters cast their vote for the candidate who allocates a higher persuasive effort to that voter during the campaign.

Our formulation features campaign expenditures that are paid for by the candidates, whereas in the Myerson framework the binding campaign promises of the winning candidate are taken from an exogenous government budget. Thus, the point of departure in our framework is that the candidates endogenously choose, and pay, their overall expenditures, and this budget choice and the choice of how to allocate the budget are made simultaneously $]^{7}$ Note, however, that in our model the campaign spending targeted to voters entails an explicit cost for the candidate and these efforts are received by the voters, regardless of who wins the election. Conversely, in Myerson (1993) the transfer promised by a candidate is paid only by the winning candidate. To summarize, our analysis can be seen as an extension of Myerson (1993) which allows for the candidates to endogenously choose their level of campaign spending, with the caveat that voters receive both candidates' targeted campaign efforts regardless of who wins the election.

Myerson (1993) has spurred a large literature on redistributive politics, including Ueda (1998) and Lizzeri (1999) that both deal with endogenous budget choice. Ueda (1998) allows candidates to choose not only the cumulative distribution of promises, but also the amount that they can take from the economy and use for making promises. This is equivalent to giving politicians the possibility of choosing their budget, but requires that the voters (rather than the politicians or parties) pay for the cost of the budget chosen by the winning candidate. He shows that Myerson's arguments on the incentives to produce favored minorities are not directly generalizable to this model.

\footnotetext{
${ }^{6}$ Lizzeri and Persico (2001) broaden this perspective by allowing candidates to use the tax revenue to target voters with or to spend it on public goods. Kovenock and Roberson (2009), and Crutzen and Sahuguet (2009) allow for inefficiencies in this process of reallocating or collecting resources. Bierbrauer and Boyer (2016) extend the analysis of Lizzeri and Persico (2001) to an environment where voters have private information about their preferences.

${ }^{7}$ With exogenous campaign budgets our setup reduces to the Myerson framework and reproduces the equilibrium results in Myerson (1993).
} 
In our model, contrary to Ueda (1998), the budget choice has an all-pay nature: campaign expenditures entail an explicit cost that directly lowers candidates' payoffs. These expenditures have to be paid for whether the candidate is elected or not, and the budgets are not generated through taxation of voters. Lizzeri (1999) extends Myerson's (1993) setup to a two-period model of "divide-the-dollar" electoral competition. In Lizzeri (1999) the budget is endogenous because politicians may increase the first-period resources available for redistributive transfers by running public debt 8 As a main result, Lizzeri (1999) shows that candidates will always raise the maximal debt, because it allows them to better target the pool of resources to voters.

Second, the endogenous choice of campaign spending in an electoral contest with persuasive efforts has been carefully studied for the case in which voters cannot be treated individually $\left.\right|^{9}$ This approach focuses on the choice of the total amount of spending, and on how the equilibrium choice of spending depends on issues such as legal spending limits or asymmetries between the candidates. From a structural point of view many of the analyses can then be interpreted as variants of the canonical models of all-pay contests, such as Tullock (1980) contest, or the all-pay auction without noise as considered by Hillman and Riley (1989) and Baye, Kovenock and deVries (1996). Hart (2016) examines the relationship between all-pay auctions and a General Lotto game with the proportional, or vote-share maximizing, objective ${ }^{10}$ and extensively studies the implications of caps on spending ${ }^{11}$ In particular Hart (2016, Theorem 6) shows that the equilibrium of a twoplayer all-pay auction coincides with the equilibrium of a corresponding General Lotto game.

Empirically, the set of voters in many elections is quite large, and recent technological advances facilitate large-scale micro-targeting of campaign resources. Some observers claim that micro-targeting of campaign spending at the level of individual voters is becoming the norm. One reading of our results is that the focus in the campaign competition literature on a single voter, or on a monolithic mass of voters is not necessarily misleading. This literature makes appropriate predictions about the overall campaign efforts, at least as long as the voter population is fully homogenous. However, that approach does not describe how and why candidates may choose different levels of voter-specific

\footnotetext{
${ }^{8}$ See Boyer and Esslinger (2016) for an extension of Lizzeri's model where politicians also have the possibility to implement a beneficial reform.

${ }^{9}$ Seminal contributions include Snyder (1989), Che and Gale (1998), Erikson and Palfrey (2000), and Meirowitz (2008). The all-pay contest nature of electoral competition has also been stressed in many other important contributions. Examples include Skaperdas and Grofman (1995), Diermeier and Myerson (1999), Pastine and Pastine (2012), Denter and Sisak (2015), and Siegel and Olszewski (2016).

${ }^{10}$ This relationship is also examined in Sahuguet and Persico (2006) and Kovenock and Roberson (2008).

${ }^{11}$ For more on the issue of caps in this environment, see Amir (2015).
} 
campaign spending to ex ante symmetric voters. We find that they do, and that this leads to electoral outcomes that are systematically characterized by unequal treatment and, in majoritarian systems, by supermajorities. In contrast to Groseclose and Snyder (1996, 2000) and Banks (2000) who address the problem of supermajorities in majoritarian systems in models with sequential choices by two asymmetric candidates, we find that supermajorities will also arise for ex-ante symmetric candidates and simultaneous campaigning choices.

One interpretation of our set-up is that we consider an all-pay auction without noise between two contestants for an infinite number of identical objects, and where each contestant's objective is to win at least $50 \%$ of the objects. A variant of this problem with a finite number of objects has been studied by Szentes and Rosenthal (2003a, 2003b). ${ }^{12}$ They examine majority auction games, which are simultaneous sealed-bid auctions of identical objects among identical bidders who each want to win a majority (or possibly a supermajority) of the objects. In the all-pay majority auction case, their setup is a finite battlefield version of our game. A key insight from Szentes and Rosenthal (2003a, 2003b) is the use of mixtures whose supports are surfaces of tetrahedra and whose best-response sets are the tetrahedra themselves. However, except in the pure chopstick case ${ }^{13}$ they have no equilibrium constructions when only two candidates compete. Our contribution is to derive the Nash equilibrium with two candidates in an environment with a continuum of objects.

Our analysis is also related to generalized or non-constant-sum Colonel Blotto and General Lotto games as in Roberson and Kvasov (2012), Washburn (2013), Amir (2015), Kovenock and Roberson (2015), and Hart (2016). In these games, the two contestants typically have exogenous budgets (or expected budgets in the General Lotto variant), simultaneously allocate their resources among the different fronts, and receive a payoff that is proportional to the number, or share, of battlefields won. In the case of the majority objective, our framework can be seen as a non-constant-sum version of this type of competition with an infinite number of fronts, a majoritarian objective function with a discontinuity at winning $50 \%$ of the battle fronts, and where players simultaneously choose both the amount of the costly resource to be mobilized and the allocation of this resource among the different fronts.

The theoretical literature on electoral competition ${ }^{14}$ includes a number of conceptual frameworks (including Downsian models of platform choice, policy motivated candidates

\footnotetext{
${ }^{12}$ See also Ewerhart (2016) who provides a new "fractal" solution to the chopsticks auction.

${ }^{13}$ This game consists of two players who compete in three simultaneous all-pay auctions for three identical objects. Each auction assigns one object. Owning one single object yields a benefit of zero. Owning two or three of the objects yields a benefit of 2 .

${ }^{14}$ For a recent survey see Dewan and Shepsle (2011).
} 
with commitment problems, and citizen-candidate models) and several potential sources of voter heterogeneity (including access to information, preferences and other dimensions). In addition, campaign contributions and campaign expenditures clearly play an important role in elections. Jacobson (2015) provides a survey addressing the issues of "where, when, for what, and for whom" campaigns matter. For example, campaign expenditures may be informative (see, e.g., Austen-Smith, 1987; Prat, 2002; Coate, 2004; Schultz, 2007) 15 In this context, micro-targeting technologies that allow the candidates to send personalized informational content to different types of voters are important tools. An analysis of this issue is provided by Schippers and Woo (2014). In contrast, we adapt the contest-theoretic perspective in the tradition of the seminal papers by Skaperdas and Grofman (1995), Che and Gale (1998), and Meirowitz (2008), in which campaign effort is persuasive, to allow for campaign efforts to also be targetable, i.e. each voter simply reacts to the amounts of persuasive campaign efforts targeted at them by each of the candidates. Micro-targeting in this context means that voters need not be heterogenous, but competing candidates may campaign for each voter separately and independently, which is, as we find, particularly important in majoritarian electoral systems.

\section{The model}

There are two candidates, or players, $A$ and $B$ and a large but finite number of voters which may be approximated by an infinite-population, of unit measure. The two players compete in an election using persuasive effort and voters are homogenous in their preferences and sensitive only to persuasive efforts. As will become clear, our model is structurally similar to the majoritarian election model in Myerson (1993), but with two major differences. In the Myerson framework candidates compete by making distribution promises that are kept if a candidate is elected. Here candidates compete with persuasive effort that is sunk and needs to be paid for also if the candidate loses the election. Further, candidates do not rely on an exogenous 'spend-it-or-lose-it' budget, but they chose their overall persuasive efforts and pay the cost of it. We also compare this majoritarian competition with a framework in which candidates maximize vote shares.

Each candidate's choice of persuasive effort per voter is described as follows. For each player $i \in\{A, B\}$, a pure strategy, which we term an effort distribution, is a distribution function $G_{i}$ of a nonnegative random variable $X_{i}$ with finite mean $E_{G_{i}}(x)$. If player $i$ has chosen $G_{i}$, then each voter receives an amount of persuasive effort that is an independent

\footnotetext{
${ }^{15}$ Herrera et al. (2008) instead focus on the mobilization aspect of campaign spending rather than on the persuasion in order to understand why campaign spending has increased at the same time that politics has become more polarized in the US.
} 
draw from player $i$ 's effort distribution $G_{i}$, where $G_{i}(x)$ denotes the probability that an arbitrary voter receives persuasive effort less than $x$ from player $i$. Let $S$ denote player $i$ 's set of pure strategies, i.e. the set of univariate distribution functions with nonnegative support and finite mean. Let $\Sigma$ denote the set of probability distributions over $S:{ }^{16}$ For each player $i$, a mixed strategy in this game is a probability distribution function $\sigma_{i} \in \Sigma$ over the set of pure strategies $S$. Let $\operatorname{Supp}\left(\sigma_{i}\right)$ denote the support of $\sigma_{i}$ (i.e. the complement of the union of all open sets of $S$ with $\sigma_{i}$-volume 0 ).

Each voter casts his vote for the candidate who expends more persuasive effort on this voter. The voter votes for $i$ if this voter receives a higher draw from $G_{i}$ than from $G_{j}$. In the event of a tie we assume that the voter uses fair randomization ${ }^{17}$ Thus, player $i$ 's vote share given that player $i$ uses the pure strategy $G_{i}$ for the random variable $X_{i}$ and player $-i$ uses $G_{-i}$ for the random variable $X_{-i}$ is

$$
\operatorname{Pr}\left[X_{i}>X_{-i}\right]+\frac{1}{2} \operatorname{Pr}\left[X_{i}=X_{-i}\right] .
$$

In the vote-share maximizing game, player $i$ 's payoff is given by

$$
\pi_{i}^{V S}\left(G_{i}, G_{-i}\right)=\operatorname{Pr}\left[X_{i}>X_{-i}\right]+\frac{1}{2} \operatorname{Pr}\left[X_{i}=X_{-i}\right]-E_{G_{i}}(x) .
$$

In the majoritarian objective game, player $i$ wins if $\operatorname{Pr}\left[X_{i}>X_{-i}\right]+\frac{1}{2} \operatorname{Pr}\left[X_{i}=X_{-i}\right]>1 / 2$, ties if $\operatorname{Pr}\left[X_{i}>X_{-i}\right]+\frac{1}{2} \operatorname{Pr}\left[X_{i}=X_{-i}\right]=1 / 2$, and loses otherwise. Let $w_{i}\left(G_{i}, G_{-i}\right)$ denote if player $i$ wins, given that player $i$ uses the pure strategy $G_{i}$ and player $-i$ uses $G_{-i}$, where

$$
w_{i}\left(G_{i}, G_{-i}\right)= \begin{cases}1 & \text { if } \operatorname{Pr}\left[X_{i}>X_{-i}\right]+\frac{1}{2} \operatorname{Pr}\left[X_{i}=X_{-i}\right]>1 / 2, \\ \frac{1}{2} & \text { if } \operatorname{Pr}\left[X_{i}>X_{-i}\right]+\frac{1}{2} \operatorname{Pr}\left[X_{i}=X_{-i}\right]=1 / 2, \\ 0 & \text { if } \operatorname{Pr}\left[X_{i}>X_{-i}\right]+\frac{1}{2} \operatorname{Pr}\left[X_{i}=X_{-i}\right]<1 / 2 .\end{cases}
$$

Player $i$ 's payoff in the majoritarian game is given by

$$
\pi_{i}^{M}\left(G_{i}, G_{-i}\right)=w_{i}\left(G_{i}, G_{-i}\right)-E_{G_{i}}(x)
$$

We define the majoritarian game with endogenous budgets as the two-player, simultaneousmove, one-shot game in which each player $i \in\{A, B\}$ chooses, possibly randomizing according to a mixed-strategy $\sigma_{i}$, an effort distribution $G_{i}$ and each player $i$ 's payoff is $\pi_{i}^{M}\left(G_{i}, G_{-i}\right)$.

\footnotetext{
${ }^{16}$ Note that a random function, or stochastic process, is a special case of a random element. Additionally, because $\Sigma$ is a separable complete metric space, every probability distribution on $\Sigma$ is tight. For further details, see Parthasarathy (1967) and Kallenberg (1997).

${ }^{17} \mathrm{As}$ is common in the literature on contests featuring the all-pay auction contest-success function, this assumption is not critical for our results which hold for a range of tie-breaking rules, and ties do not arise in equilibrium.
} 
The vote-share maximizing game with endogenous budgets is the two-player, simultaneousmove, one-shot game in which each player $i \in\{A, B\}$ chooses, possibly randomizing according to a mixed-strategy $\sigma_{i}$, distribution $G_{i}$ of persuasive effort and each player $i$ 's payoff is $\pi_{i}^{V S}\left(G_{i}, G_{-i}\right)$.

\section{Equilibrium characterization}

We begin with the characterization of equilibrium, in what turns out to be the simpler case, of the vote-share maximizing game with endogenous budgets. Next, we characterize equilibrium in the majoritarian game with endogenous budgets. Then, this section concludes with a comparison of the equilibria arising under these two objectives. Before stating our main results, it is useful to introduce some additional notation to help describe a mixed strategy in this game. Let $\eta_{i}\left(b \mid \sigma_{i}\right)=\left\{G_{i} \in S u p p\left(\sigma_{i}\right) \mid E_{G_{i}}(x)=b\right\}$ denote the set of pure strategies in the support of $\sigma_{i}$ that have the same expected cost $b$. Then, define $F_{i}(b)$ as player $i$ 's budget distribution function, which is defined as the probability that the random effort distribution $\widetilde{G}_{i}$ drawn from the mixed strategy $\sigma_{i}$ has a mean $E_{\widetilde{G}_{i}}(x)$ that is less than or equal to $b$. A key distinction between the equilibria arising under the two objectives is that in the unique equilibrium of the vote-share maximizing game, each player $i$ 's budget distribution, $F_{i}(b)$, is degenerate, whereas in any equilibrium of the majoritarian objective game, each player $i$ 's budget distribution, $F_{i}(b)$, is non-degenerate.

\subsection{Vote-Share Maximizing Game}

Recall that in the vote-share maximizing game each player $i$ 's payoff is given by equation (1).

Theorem 1 (Hillman and Riley (1989) and Baye, Kovenock, and de Vries (1996)) In the unique Nash equilibrium $\left(\sigma_{A}^{*}, \sigma_{B}^{*}\right)$ of the vote-share maximizing game with endogenous budgets, each player $i$ 's budget distribution, $F_{i}^{*}(b)$, is degenerate with all mass placed on $b=1 / 2$ and each player $i$ 's effort distribution is $G_{i}^{*}(x)=x$ for $x \in[0,1]$.

As noted in Hart (2016) 18 the vote-share maximizing game in which each player's payoff function is given by equation (1) - that is, each player maximizes his vote-share and both players pay their expected effort - is strategically equivalent to a symmetric two-player all-pay auction with complete information, in which each player has a payoff of 1 from winning the auction. Thus, equilibrium is characterized by Hillman and

\footnotetext{
${ }^{18}$ See Section 3 of Hart (2016).

${ }^{19}$ See Theorem 6, and its corresponding proof, of Hart (2016) for a new method of characterizing equilibria.
} 
Riley (1989) and Baye, Kovenock, and de Vries (1996). In the unique pure-strategy Nash equilibrium $\left(G_{A}^{*}, G_{B}^{*}\right)$ of the vote-share maximizing game with endogenous budgets, each player $i$ 's effort distribution is $G_{i}^{*}(x)=x$ for $x \in[0,1]$.

For intuition on this result, assume for a moment that the set of voters is finite with $n$ identical voters 20 Vote-share maximization then means that candidates attribute the same fixed value to winning the vote of each of these voters, and this value is independent of how many of the other votes they win. This implies that the game may be interpreted as a contest between two players who compete for $n$ identical prizes in $n$ identical and independent all-pay auctions. Suppose that a value of $1 / n$ is attributed to winning any single of these votes. We know from Baye et al. (1996) that the unique equilibrium in each of the $n$ parallel all-pay auctions is in mixed strategies with $G_{i}^{*}(x)=x$ for $x \in\left[0, \frac{1}{n}\right]$. This has implications for the equilibrium vote share and for the players' equilibrium persuasive campaign efforts. For each player, the sum of the average efforts across the $n$ all-pay auctions is $\frac{1}{2} \frac{1}{n} n=\frac{1}{2}$. Similarly, for each player, the sum of the expected winnings across the $n$ all-pay auctions, which corresponds to the sum of the expected votes won by the player, is $\frac{1}{2} \frac{1}{n} n=\frac{1}{2}$.

For the case of a continuum of voters, we follow the convention of the redistributive politics literature originating with Myerson (1993) in which it is assumed that each player chooses a one-dimensional effort distribution, possibly according to a mixed strategy. In the context of targetable, persuasive campaign effort, the effort that a player allocates to any given voter is an independent draw from that player's effort distribution. As noted in Myerson (1993), and emphasized in Hart (2008, 2016), this continuum voter convention may be interpreted as competition over a single, representative, voter but where each player pays their expected effort. That is, let $n=1$ in the example given above with $n$ identical voters and have each player pay their expected bid rather than the bid drawn from their distribution of bids. Because the costs of bids are linear and each player is risk-neutral, it follows directly that the payoff function given in equation (1) is equivalent to the expected payoff in a single all-pay auction with prize value 1 where each player $i$ pays the random bid drawn from their bid distribution $G_{i}^{*}(x)$.

\subsection{Majoritarian Game: Main Results}

Theorem 2 completely characterizes the properties of the equilibrium budget distribution $F_{i}^{*}(b)$ and equilibrium parametric family of effort distributions $\left\{\eta_{i}^{*}\left(b \mid \sigma_{i}\right) \mid b \in \operatorname{Supp}\left(F_{i}^{*}\right)\right\}$ that hold in any Nash equilibrium $\left(\sigma_{A}^{*}, \sigma_{B}^{*}\right)$.

\footnotetext{
${ }^{20}$ Note that this corresponds to a version of the (endogenous-budget) non-constant-sum Colonel Blotto Game examined in Roberson and Kvasov (2012) in which neither player has a cap on resource expenditures.
} 
Theorem 2 In any Nash equilibrium $\left(\sigma_{A}^{*}, \sigma_{B}^{*}\right)$ of the majoritarian game with endogenous budgets, each player $i$ 's budget distribution is $F_{i}^{*}(b)=b$ for $b \in[0,1]$ and each player $i$ 's family of effort distributions is, for almost every $b \in[0,1], \eta_{i}^{*}\left(b \mid \sigma_{i}^{*}\right)=\left\{G_{i}^{*}(x \mid b)\right\}$ where $G_{i}^{*}(x \mid b)=x / 2 b$ for $x \in[0,2 b]$.

The proof of Theorem 2 is given in the Appendix. From Theorem 2 we see that equilibrium in the majoritarian game with endogenous budgets builds upon the intuition of the multidimensional strategic resource allocation competition of Myerson (1993) in which budgets are exogenous and use-it-or-lose-it — combined with the strategic resource expenditure competition of the all-pay auction with complete information as in Baye, Kovenock and de Vries (1996). That is, one element is the equilibrium parametric family of effort distributions $\left\{\eta_{i}^{*}\left(b \mid \sigma_{i}\right) \mid b \in[0,1]\right\}$, which is related to the literature on Colonel Blotto games (Gross and Wagner 1950; Shubik 1970; Myerson 1993; Roberson 2006). The second element is the budget distribution $F_{i}^{*}(b)$, which coincides with the unique equilibrium strategy in a two-player, symmetric, all-pay auction with complete information in which each player has a value of one for the object being auctioned (Hillman and Riley 1989; Baye, Kovenock, de Vries 1996; Siegel 2009).

For intuition on why any pair of mixed strategies $\left(\sigma_{A}, \sigma_{B}\right)$ that satisfies the conditions in Theorem 2 forms an equilibrium, suppose that player $-i$ is using a mixed strategy $\sigma_{-i}$ that satisfies the conditions of Theorem 2, Player $i$ 's expected payoff from any pure strategy $G_{i}$ with finite mean $E_{G_{i}}(x)$ is,

$$
E_{\sigma_{-i}}\left(\pi_{i}^{M}\left(G_{i}, G_{-i}\right)\right)=E_{\sigma_{-i}}\left(w_{i}\left(G_{i}, G_{-i}\right)\right)-E_{G_{i}}(x) .
$$

To calculate $E_{\sigma_{-i}}\left(w_{i}\left(G_{i}, G_{-i}^{*}\right)\right)$, it is useful to first establish a fact, formally stated below, that provides insight into the problem of calculating a best-response when your opponent is using a strategy that satisfies the conditions in Theorem 2, In the statement of Fact 1, we restrict our focus to any arbitrary effort distribution $G_{i}(x)$ with $E_{G_{i}}(x) \leq 1$. Because there exists a $G_{i}(x)$ with $E_{G_{i}}(x)=1$ - namely $G_{i}(x)=x / 2$ for $x \in[0,2]$ - such that player $i$ wins a majority of the votes against almost every $G_{i}^{*}(x \mid b), b \in[0,1]$, player $i$ has no incentive to choose a $G_{i}(x)$ with $E_{G_{i}}(x)>1$.

Fact 1 If player $-i$ uses a strategy $\sigma_{-i}^{*}$ that satisfies the conditions in Theorem 2 and player $i$ uses an arbitrary effort distribution $G_{i}$ with $E_{G_{i}}(x) \leq 1$, then there exists a budget level $\hat{b} \leq E_{G_{i}}(x)$ such that $E_{\sigma_{-i}^{*}}\left(w_{i}\left(G_{i}, G_{-i}^{*}\right)\right)=F_{-i}^{*}(\hat{b})$.

Fact 1 is a fairly straightforward consequence of player $-i$ using a strategy $\sigma_{-i}^{*}$ that satisfies the conditions in Theorem 2 , but it is useful to provide a sketch of the argument. It consists of two parts: a single-crossing condition with regards to budgets - that is, there exists a single-crossing point $\hat{b}$ such that player $i$ wins a majority of votes if player 
$-i$ 's random budget $\widetilde{b}_{-i}$ satisfies $\widetilde{b}_{-i}<\hat{b}-$ and a condition on where the single crossing point occurs.

We begin with part 1 , or the single-crossing condition. Note that player $-i$ 's parametric family of effort distributions $\left\{G_{-i}^{*}(x \mid b) \mid b \in[0,1]\right\}$ satisfies the property that for each $b^{\prime}>b$ it is the case that $G_{-i}^{*}\left(x \mid b^{\prime}\right)<G_{-i}^{*}(x \mid b)$ for all strictly positive points in $\operatorname{Supp}\left(G_{-i}^{*}(x \mid b)\right)$ and $G_{-i}^{*}\left(0 \mid b^{\prime}\right)=G_{-i}^{*}(0 \mid b)$ - i.e. $G_{-i}^{*}\left(x \mid b^{\prime}\right)$ first-order stochastically dominates $\left.G_{-i}^{*}(x \mid b)\right)$. We therefore know that for any pure strategy $G_{i}$ player $i$ 's vote share ${ }^{21}$ satisfies the following property

$$
\begin{aligned}
\operatorname{Pr}\left[X_{i}>X_{-i} \mid G_{i}, G_{-i}^{*}\left(x \mid b^{\prime}\right)\right] & =1-\int G_{i}(x) d G_{-i}^{*}\left(x \mid b^{\prime}\right) \leq \\
1 & -\int G_{i}(x) d G_{-i}^{*}(x \mid b)=\operatorname{Pr}\left[X_{i}>X_{-i} \mid G_{i}, G_{-i}^{*}(x \mid b)\right],
\end{aligned}
$$

where $G_{i}(x)$ is weakly increasing because it is a cumulative distribution function. It follows from equation (4) that $\operatorname{Pr}\left[X_{i}>X_{-i} \mid G_{i}, G_{-i}^{*}(x \mid b)\right]$ is weakly decreasing in $b$. We define $\hat{b}$ a: 22

$$
\hat{b} \equiv \max \left\{b \in[0,1] \mid \operatorname{Pr}\left[X_{i}>X_{-i} \mid G_{i}, G_{-i}^{*}(x \mid b)\right] \geq 1 / 2\right\} .
$$

Clearly, there exists such a $\hat{b}$, and it follows that $E_{\sigma_{-i}}\left(w_{i}\left(G_{i}, G_{-i}^{*}\right)\right)=F_{-i}^{*}(\hat{b})$. We now show that the point $\hat{b}$ satisfies $\hat{b} \leq E_{G_{i}}(x)$. By way of contradiction suppose that $\hat{b}>$ $E_{G_{i}}(x)$. Because

$$
\hat{b}>E_{G_{i}}(x)=\int_{0}^{\infty} x d G_{i}(x)=\int_{0}^{2 \hat{b}} x d G_{i}(x)+\int_{2 \hat{b}}^{\infty} x d G_{i}(x),
$$

it follows that

$$
\hat{b}-\int_{2 \hat{b}}^{\infty} x d G_{i}(x)>\int_{0}^{2 \hat{b}} x d G_{i}(x)
$$

Next, recall that

$$
\begin{aligned}
\operatorname{Pr}\left[X_{i}>X_{-i} \mid G_{i}, G_{-i}^{*}(x \mid b)\right] & =\int_{0}^{\infty} G_{-i}(x \mid b) d G_{i}(x) \\
& =\frac{1}{2 b} \int_{0}^{2 b} x d G_{i}(x)+\int_{2 b}^{\infty} d G_{i}(x) .
\end{aligned}
$$

Then, inserting equation (7) into equation (9), it follows that

$$
\begin{aligned}
\operatorname{Pr}\left[X_{i}>X_{-i} \mid G_{i}, G_{-i}^{*}(x \mid \hat{b})\right] & =\frac{1}{2 \hat{b}} \int_{0}^{2 \hat{b}} x d G_{i}(x)+\int_{2 \hat{b}}^{\infty} d G_{i}(x) \\
& <\frac{1}{2}+\int_{2 \hat{b}}^{\infty}\left(1-\frac{x}{2 \hat{b}}\right) d G_{i}(x)
\end{aligned}
$$

\footnotetext{
${ }^{21}$ Because $G_{-i}^{*}(x \mid b)$ does not place strictly positive mass on any point $x \in[0,2 b]$, $\operatorname{Pr}\left[X_{i}=X_{-i} \mid G_{i}, G_{-i}^{*}(x \mid b)\right]=0$. That is, ties in persuasive effort arise with probability zero.

${ }^{22}$ In the case that $\operatorname{Pr}\left[X_{i}>X_{-i} \mid G_{i}, G_{-i}^{*}(x \mid b)\right]<1 / 2$ for all $b \in[0,1]$, let $\hat{b}=0$.
} 
Because $1-\frac{x}{2 \hat{b}}<0$ for all $x>2 \hat{b}$, it follows from equation 11 that $\operatorname{Pr}\left[X_{i}>X_{-i} \mid G_{i}, G_{-i}^{*}(x \mid \hat{b})\right]$ is strictly less than $1 / 2$, which is a contradiction to the definition of $\hat{b}$ in equation (5). It, therefore, follows that $\hat{b} \leq E_{G_{i}}(x)$.

We now utilize Fact 1 to examine player $i$ 's problem of calculating a best-response when player $-i$ is using a strategy $\sigma_{-i}^{*}$ that satisfies the conditions in Theorem 2. Combining Fact 1 with equation (3) player $i$ 's expected payoff from any pure strategy $G_{i}$ is given by

$$
E_{\sigma_{-i}^{*}}\left(\pi_{i}^{M}\left(G_{i}, G_{-i}^{*}\right)\right)=F_{-i}^{*}(\hat{b})-E_{G_{i}}(x) .
$$

where $\hat{b}$ is defined in equation (5). Note that because $F_{-i}^{*}(\hat{b})=\hat{b}$ and $\hat{b} \leq E_{G_{i}}(x)$, player $i$ 's maximum payoff from any pure strategy $G_{i}$ is 0 . Next, it follows from equation (10), together with the definition of $\hat{b}$ in equation (5), that if $\operatorname{Supp}\left(G_{i}\right) \subseteq\left[0,2 E_{G_{i}}(x)\right]$, then $\hat{b}=E_{G_{i}}(x)$ and player $i$ 's expected payoff, see equation 12 , is 0 . To summarize, if player $-i$ is using a strategy $\sigma_{-i}^{*}$ that satisfies the conditions in Theorem 2 , then any effort distribution $G_{i}$ with finite mean $E_{G_{i}}(x) \leq 1$ and $\operatorname{Supp}\left(G_{i}\right) \subseteq\left[0,2 E_{G_{i}}(x)\right]$ provides player $i$ with his maximal expected payoff of zero. Because the Theorem 2 condition that for all $b \in[0,1], G_{i}^{*}(x \mid b)=x / 2 b$ for $x \in[0,2 b]$ implies that $E_{G_{i}^{*}}(x) \leq 1$ and $\operatorname{Supp}\left(G_{i}^{*}\right) \subseteq\left[0,2 E_{G_{i}^{*}}(x)\right]$ for all $G_{i}^{*} \in \sigma_{i}$, any strategy $\sigma_{i}$ satisfying the conditions in Theorem 2 is a best response for player $i$.

One important insight that follows from Fact 1 is that in the majoritarian game with endogenous budgets the problem of constructing a best-response to an equilibrium strategy, characterized in Theorem 2, can be decomposed into two distinct components: a budget choice problem and a budget allocation problem.

To illustrate this point, consider first the following game which eliminates the budget choice problem and focuses solely on the budget allocation problem. We define the majoritarian game with incomplete information regarding the players' exogenous use-itor-lose-it budgets as the two-player simultaneous-move game in which each player $i$ 's use-it-or-lose-it budget $b_{i}$ is private information and assumed to be drawn according to a common distribution function $F$ - satisfying $\operatorname{Supp}(F)=[0,1], F(0)=0$, and with strictly positive and continuously differentiable probability density function $f$ - each player chooses an effort distribution $G_{i}$ with mean $E_{G_{i}}(x) \leq b_{i}$, and each player $i$ 's payoff is $w_{i}\left(G_{i}, G_{-i}\right)$. The equilibrium of this version of the majoritarian game is provided in Corollary 1.

Corollary 1 There exists a unique pure-strategy Bayesian-Nash equilibrium of the majoritarian game with incomplete information regarding the players' exogenous use-it-orlose-it budgets in which for each $b_{i} \in[0,1]$ each player $i$ 's effort distribution is $G_{i}^{*}\left(x \mid b_{i}\right)=$ $x / 2 b_{i}$ for $x \in\left[0,2 b_{i}\right]$. 
From Fact 1, we know that if player $i$ 's budget type is $b_{i}$, then the maximum payoff that player $i$ can achieve - given that player $-i$ is using a family of distributions that satisfies the conditions in Corollary 1 - is $E\left(w_{i}\left(G_{i}\left(x \mid b_{i}\right), G_{-i}^{*}\left(x \mid b_{-i}\right)\right)\right)=F\left(b_{i}\right)$. Furthermore, a family of distributions that satisfies the conditions in Corollary 1 is a best-response for player $i$ that achieves this maximum payoff. Thus, the proof that a combination of strategies $\left(G_{A}^{*}(x \mid b), G_{B}^{*}(x \mid b)\right)$ satisfying the conditions in Corollary 1 forms an equilibrium follows directly from Fact 1 . Given the common distribution $F$ of each player's private level of use-it-or-lose-it resources, the proof of uniqueness can be directly constructed from the Theorem 2 proof of uniqueness in the Appendix (see Lemmas 8-13).

Returning to the problem of constructing a best-response to an equilibrium strategy in the majoritarian game with endogenous budgets and given Corollary 1's characterization of equilibrium in the budget allocation component of the best-response problem, we now examine the budget choice component. Given that each player is using a family of effort distributions that satisfy the conditions in Theorem 2, player $i$ wins against player $-i$ whenever player $i$ 's budget exceeds that of $-i$ by an arbitrarily small but positive $\varepsilon$. Moreover, player $i$ 's expected payoff from any budget level $b_{i} \in[0,1]$ is, from equation (12), equal to 0 . Thus, player $i$ is indifferent between all budget levels $b_{i} \in[0,1]$, and strictly prefers any such budget level to $b_{i}>1$. This provides intuition for why the equilibrium budget distributions $F_{i}^{*}$ and $F_{-i}^{*}$ coincide with the equilibrium strategies in the symmetric two-player all-pay auction, and, thus, why any strategy $\sigma_{i}$ satisfying the conditions in Theorem 2 provides a best response for player $i$ in both the budget allocation and budget choice components of his problem.

\subsection{Comparison of Equilibria Across Electoral Systems}

Theorems 1 and 2 have a number of interesting implications. First, they reveal that in the equilibrium of both the vote-share maximizing and majoritarian games the two candidates fully dissipate, in expectation, the rent from winning office. That is, under each objective, each of the players chooses a budget that is, on average, equal to $1 / 2$ the value of the prize of winning office, and each of them wins with probability $1 / 2$.

Theorems 1 and 2 are also important for the large literature that looks at campaigning as an all-pay contest. Much of this literature either considers a black-box voting mechanism in which campaign budget choices turn into winning probabilities or it applies the assumption that each candidate's campaign expenditure must be the same for each voter or, at least, be the same for each voter within each identifiable group of voters. In our framework, candidates have an incentive to "cultivate favored minorities" as in Myerson (1993). That is, the candidates have incentive to randomly target their persuasive campaign efforts at individual voters by allocating their efforts via a non-degenerate effort 
distribution function, $G_{i}^{*}(\cdot \mid \cdot)$, such that different voters receive different levels of effort, or attention, with some voters receiving high levels of persuasive campaign effort, or attention, and others receiving low levels. Despite the ability to randomly target campaign efforts across an otherwise homogeneous electorate (i.e. $G_{i}^{*}(\cdot \mid \cdot)$ is non-degenerate), we find that under the majoritarian objective the equilibrium budget distribution functions, $F_{i}^{*}$, are remarkably similar to those arising in an environment in which expenditures must be symmetric across voters.

In the unique equilibrium of the vote-share maximizing game each player wins, with probability one, exactly half of the votes. Thus, supermajorities do not arise in the vote-share maximizing game. Conversely, supermajorities are an important and puzzling phenomenon in majoritarian systems. If 50.1 percent of the votes is enough to win, if it is expensive to campaign and acquire votes, and if candidates have the ability to, stochastically, treat different voters differently, why would the equilibrium outcome often be characterized by one party receiving far more than half of the votes? The following proposition shows the implications of Theorem 2 for the emergence of supermajorities. In the statement of Proposition 1, it will be convenient to use $\beta_{i}$ to denote player $i$ 's vote share $\operatorname{Pr}\left[X_{i}>X_{-i} \mid G_{i}, G_{-i}^{*}(x \mid \hat{b})\right]$.

Proposition 1 In any equilibrium $\left(\sigma_{A}^{*}, \sigma_{B}^{*}\right)$ of the majoritarian game, the probability of the winner's vote share, denoted $\beta_{A}$ and $\beta_{B}$, being greater than or equal to $\bar{\beta} \in(1 / 2,1)$ is

$$
\operatorname{prob}\left(\max \left\{\beta_{A}, \beta_{B}\right\} \geq \bar{\beta}\right)=2(1-\bar{\beta}) .
$$

From Theorem 2]s characterization of equilibrium, it, intuitively, follows that the uncoordinated mixed-strategies of $A$ and $B$ yield unequal budgets, and these translate into unequal vote shares.

Our result offers a new solution to the puzzle described by Groseclose and Snyder (1996, 2000) and Banks (2000), but for the case of simultaneous budget choices by the two candidates. Groseclose and Snyder offer a possible solution that relies on the assumption that the two candidates move sequentially, i.e., for a situation in which the challenger commits to his own expenditure level after the incumbent chooses his expenditure level. Our results provide a new answer to this question.

\section{Loyalty, micro-targeting, and private information}

Now we examine the case that each voter's evaluation of a candidate may depend upon the combination of the transfer from the candidate and the candidate's identity. We introduce this possibility in our framework by allowing voters to either be of the loyal, 
or partisan, type - in which case they are loyal to a single candidate and vote for that candidate regardless of the candidates' persuasive efforts — or of the swing, or independent, type - in which case the voter votes for the candidate that provides him with the higher persuasive effort, regardless of that candidate's identity. For simplicity, we assume that each voter is either loyal to candidate $A$, or a swing voter ${ }^{23}$ Loyalty for party $A$ is independently and identically distributed across voters and each voter is a loyal voter for party $A$ with probability $\Delta \in\left[0, \frac{1}{2}\right){ }^{24}$ The targetability of persuasive campaign effort depends upon the level of information available to candidates regarding voters' types, or characteristics. We examine this issue at two points on the spectrum of available information: coarse information and perfect information.

\subsection{Coarse information of voter loyalty}

With coarse information, candidates know the aggregate share $\Delta$ of loyal voters, but whether a specific voter is a loyal voter or a swing voter is unobservable to each of the candidates. Thus, each candidate $i$ chooses, possibly randomizing according to a mixed strategy $\sigma_{i}$, an effort distribution $G_{i}$ and each voter (loyal or swing) makes an independent draw from $G_{i}$. Given the presence of voter partisanship, let $w_{A}^{P}\left(G_{A}, G_{B}\right)$ denote if player $A$ wins a majority of the votes, given that player $A$ uses the pure strategy $G_{A}$ and player $B$ uses $G_{B}$, where

$$
w_{A}^{P}\left(G_{A}, G_{B}\right)= \begin{cases}1 & \text { if } \Delta+(1-\Delta) \operatorname{Pr}\left[X_{A}>X_{B}\right]+\frac{1-\Delta}{2} \operatorname{Pr}\left[X_{A}=X_{B}\right]>\frac{1}{2}, \\ \frac{1}{2} & \text { if } \Delta+(1-\Delta) \operatorname{Pr}\left[X_{A}>X_{B}\right]+\frac{1-\Delta}{2} \operatorname{Pr}\left[X_{A}=X_{B}\right]=\frac{1}{2}, \\ 0 & \text { if } \Delta+(1-\Delta) \operatorname{Pr}\left[X_{A}>X_{B}\right]+\frac{1-\Delta}{2} \operatorname{Pr}\left[X_{A}=X_{B}\right]<\frac{1}{2} .\end{cases}
$$

and let $w_{B}^{P}\left(G_{B}, G_{A}\right)$ be defined as $1-w_{A}^{P}\left(G_{A}, G_{B}\right)$. Player $i$ 's payoff in the majoritarian game with endogenous budgets, partisan voters, and coarse information is given by

$$
\pi_{i}^{M C}\left(G_{i}, G_{-i}\right)=w_{i}^{P}\left(G_{i}, G_{-i}\right)-E_{G_{i}}(x)
$$

The following proposition shows how the combination of partisanship that generates an advantage for candidate $\mathrm{A}$ and coarse information regarding this advantage translates into equilibrium vote-buying budgets and distributions of payments.

\footnotetext{
${ }^{23}$ For simplicity, we consider the case in which only candidate $A$ has loyal voters. But the analysis can be extended, with some notational effort, to allow both candidates to have strictly positive shares of loyal voters.

${ }^{24}$ If $\Delta \geq \frac{1}{2}$ the problem degenerates and becomes uninteresting. The pivotal voter would be loyal in this case, and any vote-buying effort would be fully wasted. Vote buying and budget choices would be inconsequential for the majority game.
} 
Proposition 2 In any Nash equilibrium $\left(\sigma_{A}^{*}, \sigma_{B}^{*}\right)$ of the majoritarian game with endogenous budgets, partisan voters, and coarse information player A's budget distribution is

$$
F_{A}^{*}(b)=\left\{\begin{array}{ccc}
\frac{b}{\frac{1-2 \Delta}{1-\Delta}} & \text { for } \quad b \in\left[0, \frac{1-2 \Delta}{1-\Delta}\right) \\
1 & \text { for } \quad b \geq \frac{1-2 \Delta}{1-\Delta}
\end{array},\right.
$$

and player $A$ 's family of effort distributions is, for almost every $b \in[0,1-2 \Delta / 1-\Delta], \eta_{A}^{*}\left(b \mid \sigma_{A}^{*}\right)=$ $\left\{G_{A}^{*}(x \mid b)\right\}$ where

$$
G_{A}^{*}(x \mid b)=\left\{\begin{array}{ccc}
1-\frac{1-2 \Delta}{1-\Delta}+\frac{1-2 \Delta}{1-\Delta} \frac{x}{2 b \frac{1-\Delta}{1-2 \Delta}} & \text { for } & x \in\left[0,2 b \frac{1-\Delta}{1-2 \Delta}\right] \\
1 & \text { for } & x>2 b \frac{1-\Delta}{1-2 \Delta}
\end{array},\right.
$$

Similarly, player B's budget distribution is

$$
F_{B}^{*}(b)=\left\{\begin{array}{ccc}
1-\frac{1-2 \Delta}{1-\Delta}+\frac{b}{\frac{1-\Delta}{1-2 \Delta}} & \text { for } & b \in[0,1) \\
1 & \text { for } & b \geq 1
\end{array}\right.
$$

and player $B$ 's family of effort distributions is, for almost every $b \in[0,1], \eta_{B}^{*}\left(b \mid \sigma_{B}^{*}\right)=$ $\left\{G_{B}^{*}(x \mid b)\right\}$ where

$$
G_{B}^{*}(x \mid b)=\left\{\begin{array}{rcc}
\frac{x}{2 b} & \text { for } & y \in[0,2 b] \\
1 & \text { for } & x>2 b
\end{array} .\right.
$$

Expected campaign budgets are the same for the two candidates and given by

$$
\frac{1-2 \Delta}{2(1-\Delta)}
$$

Expected payoffs in equilibrium are

$$
\pi_{A}=\frac{\Delta}{1-\Delta} \text { and } \pi_{B}=0
$$

There are different ways in which having loyal voters may be advantageous: it could increase $A$ 's equilibrium winning probability, it could reduce the amount of campaign spending that is needed by candidate $A$ to win, or it could affect both the winning probability and the persuasive campaign expenditure. Proposition 2 shows that, with coarse information, the advantaged candidate benefits in terms of winning probability. Candidate $A$ wins with a higher probability, but both candidates choose the same expected budget size. This equilibrium outcome is characterized by candidates with a stronger electoral base winning more often, and with a campaign budget that does not necessarily exceed the campaign budget of the underdog candidate. Note also that the presence of a loyalty advantage for player $A$ makes the electoral competition less competitive, and, thus, both players spend less than in the symmetric game without partisanship.

For intuition regarding the equilibrium strategies characterized in Proposition 2, we begin by noting that Fact 1 and Corollary 1, can be extended, as described below, to 
the case of partisan voters and coarse information. Recall that Corollary 1 examined a related game - an incomplete information version of the majoritarian game in which each player has private information regarding his exogenous use-it-or-lose-it budget that removes the endogenous budget choices of the original game and establishes that the Theorem 1 effort distributions are the unique equilibrium of this incomplete information version of the game. Corollary 2 extends this result to the case of partisan voters and coarse information and shows that the Proposition 2 effort distributions are the unique equilibrium of this incomplete information version of the game.

Corollary 2 Suppose that each player i's exogenous use-it-or-lose-it budget $b_{i}$ is drawn according to his Proposition 2 budget distribution $F_{i}^{*}$. There exists a unique pure-strategy Bayesian-Nash equilibrium of the majoritarian game with incomplete information regarding the players' exogenous use-it-or-lose-it budgets and coarse information regarding voter loyalty in which for each $b_{i} \in[0,1]$ each player $i$ 's effort distribution is his Proposition 2 effort distribution $G_{i}^{*}\left(x \mid b_{i}\right)$.

The key step in modifying Corollary 1 to allow for voter loyalty is extending Fact 1 to allow for voter loyalty, which we denote as Fact 2.

Fact 2 If player $A$ uses a strategy $\sigma_{A}^{*}$ that satisfies the conditions in Proposition 2 and player $B$ uses any effort distribution $G_{B}$ with $E_{G_{B}}(x) \leq 1$, then there exists a budget level $\hat{b}_{B} \leq(1-2 \Delta) E_{G_{B}}(x) /(1-\Delta)$ such that $E_{\sigma_{A}^{*}}\left(w_{B}^{P}\left(G_{B}, G_{A}^{*}\right)\right)=F_{A}^{*}\left(\hat{b}_{B}\right)$. Similarly, if player $B$ uses a strategy $\sigma_{B}^{*}$ that satisfies the conditions in Proposition 2 and player $A$ uses any effort distribution $G_{A}$ with $E_{G_{A}}(x) \leq(1-2 \Delta) /(1-\Delta)$, then there exists a budget level $\hat{b}_{A} \leq(1-\Delta) E_{G_{A}}(x) /(1-2 \Delta)$ such that $E_{\sigma_{B}^{*}}\left(w_{A}^{P}\left(G_{A}, G_{B}^{*}\right)\right)=F_{B}^{*}\left(\hat{b}_{A}\right)$.

The single-crossing portion of Fact 2 follows along the same lines as for Fact 1. Beginning with player $B$ and his point $\hat{b}_{B}$ at which crossing occurs, define $\hat{b}_{B}$ as

$$
\hat{b}_{B} \equiv \max \left\{b \in[0,1] \mid(1-\Delta) \operatorname{Pr}\left[X_{B}>X_{A} \mid G_{B}, G_{A}^{*}(x \mid b)\right] \geq 1 / 2\right\} .
$$

To show that $\hat{b}_{B} \leq(1-2 \Delta) E_{G_{B}}(x) /(1-\Delta)$, by way of contradiction suppose that

$$
\hat{b}_{B}>\frac{(1-2 \Delta) E_{G_{B}}(x)}{(1-\Delta)} \text {. }
$$

Then, because

$$
E_{G_{B}}(x)=\int_{0}^{\infty} x d G_{i}(x)=\int_{0}^{\frac{2(1-\Delta) \hat{b}_{B}}{1-2 \Delta}} x d G_{B}(x)+\int_{\frac{2(1-\Delta) \hat{b}_{B}}{1-2 \Delta}}^{\infty} x d G_{B}(x),
$$

it follows from equations $(22)$ and $(23)$ that

$$
\left(\frac{1-\Delta}{1-2 \Delta}\right) \hat{b}_{B}-\int_{\frac{2(1-\Delta) \hat{b}_{B}}{1-2 \Delta}}^{\infty} x d G_{B}(x)>\int_{0}^{\frac{2(1-\Delta) \hat{b}_{B}}{1-2 \Delta}} x d G_{B}(x) .
$$


Next, recall that

$$
\begin{aligned}
(1-\Delta) \operatorname{Pr}\left[X_{B}\right. & \left.>X_{A} \mid G_{B}, G_{A}^{*}(x \mid b)\right]=(1-\Delta) \int_{0}^{\infty} G_{A}^{*}(x \mid b) d G_{B}(x) \\
& =\int_{0}^{\frac{2(1-\Delta) b}{1-2 \Delta}}\left[\Delta+\frac{(1-2 \Delta)^{2}}{(1-\Delta)} \frac{x}{2 b}\right] d G_{B}(x)+(1-\Delta) \int_{\frac{2(1-\Delta) b}{1-2 \Delta}}^{\infty} d G_{B}(x) .
\end{aligned}
$$

Then, inserting equation (24) into the second line of equation (25), it follows that

$$
\begin{aligned}
& (1-\Delta) \operatorname{Pr}\left[X_{B}>X_{A} \mid G_{B}, G_{A}^{*}\left(x \mid \hat{b}_{B}\right)\right]< \\
& \quad \frac{1}{2}-\Delta+\Delta \int_{0}^{\frac{2(1-\Delta) \hat{b}_{B}}{1-2 \Delta}} d G_{B}(x)+\int_{\frac{2(1-\Delta) \hat{b}_{B}}{1-2 \Delta}}^{\infty}\left(1-\Delta-\frac{(1-2 \Delta)^{2}}{(1-\Delta)} \frac{x}{2 \hat{b}_{B}}\right) d G_{B}(x) .
\end{aligned}
$$

Because $1-\Delta-\frac{(1-2 \Delta)^{2}}{(1-\Delta)} \frac{x}{2 \hat{b}_{B}}<\Delta$ for all $x>\frac{2(1-\Delta) \hat{b}_{B}}{(1-2 \Delta)}$, it follows from equation 26 that $(1-\Delta) \operatorname{Pr}\left[X_{B}>X_{A} \mid G_{B}, G_{A}^{*}\left(x \mid \hat{b}_{B}\right)\right]$ is strictly less than $1 / 2$, which is a contradiction to the definition of $\hat{b}_{B}$ in equation 21). Thus, it follows that $\hat{b}_{B} \leq(1-2 \Delta) E_{G_{B}}(x) /(1-\Delta)$.

Combining equation (21) with equation (14) player $B$ 's expected payoff from any pure strategy $G_{B}$ is given by

$$
E_{\sigma_{A}^{*}}\left(\pi_{B}^{M C}\left(G_{B}, G_{A}^{*}\right)\right)=F_{A}^{*}\left(\hat{b}_{B}\right)-E_{G_{B}}(x) .
$$

In addition, for any effort distribution $G_{B}$ with finite mean $E_{G_{B}}(x) \leq 1-\Delta$ and $\operatorname{Supp}\left(G_{B}\right) \subseteq\left[0,2 E_{G_{B}}(x)\right]$ it follows that $\hat{b}_{B}=(1-2 \Delta) E_{G_{B}}(x) /(1-\Delta)$ and player $B$ 's expected payoff, from equation (27), is

$$
E_{\sigma_{A}^{*}}\left(\pi_{B}^{M C}\left(G_{B}, G_{A}^{*}\right)\right)=F_{A}^{*}\left((1-2 \Delta) E_{G_{B}}(x) /(1-\Delta)\right)-E_{G_{B}}(x),
$$

which is equal to 0 because $F_{A}^{*}(b)=b(1-\Delta) /(1-2 \Delta)$ for $b \in[0,(1-2 \Delta) /(1-\Delta)]$.

To summarize, if player $A$ is using a strategy $\sigma_{A}$ that satisfies the conditions in Proposition 2 , then any effort distribution $G_{B}$ with finite mean $E_{G_{B}}(x) \leq 1$ and $\operatorname{Supp}\left(G_{B}\right) \subseteq$ $\left[0,2 E_{G_{B}}(x)\right]$ - which is satisfied for each of player $B$ 's Corollary 2 effort distributions $G_{B}^{*}(x \mid b)$ - provides player $B$ with his maximal expected payoff of zero and is a best response for player $B$. The case for player $A$ and $\hat{b}_{A}$ follows along similar lines. The proof of uniqueness in the majoritarian game with incomplete information follows along the same lines as that for Theorem 2, i.e. Lemmas 8-13 in the Appendix.

For intuition on the Proposition 2 equilibrium budget distributions, it is useful to briefly consider a special case of an unfair all-pay auction between players $A$ and $B$. If player $A$ bids $b_{A}$ and player $B$ bids $b_{B}$, then player $A$ wins the all-pay auction if $b_{A}>\gamma b_{B}$ where $\gamma \leq 1$ corresponds to an effectiveness of bids advantage for player $A$. In the case of a tie we assume that the winner is randomly chosen. From Konrad (2002), we have the following result. 
Result 1 (Konrad, 2002) For a prize value of $V$ and $\gamma \leq 1$ the unique mixed-strategy Nash equilibrium is characterized as follows,

$$
F_{A}^{*}(b)=\left\{\begin{array}{lll}
\frac{b}{\gamma V} & \text { for } & b \in[0, \gamma V), \\
1 & \text { for } & b \geq \gamma V
\end{array}\right.
$$

and

$$
F_{B}^{*}(b)=\left\{\begin{array}{lll}
1-\gamma+\frac{\gamma x}{V} & \text { for } & b \in[0, V), \\
1 & \text { for } \quad b \geq V .
\end{array}\right.
$$

Player A's expected payoff and expected bid are $(1-\gamma) V$ and $\gamma V / 2$, respectively. Similarly, player $B$ 's expected payoff and expected bid are 0 and $\gamma V / 2$, respectively.

From Result 1, it is clear that the Proposition 2 budget distributions $F_{A}^{*}$ and $F_{B}^{*}$ correspond to the equilibrium in an unfair all-pay auction in which player $A$ is the advantaged player, $V=1$ and $\gamma=\frac{1-2 \Delta}{1-\Delta}$. That is, although the presence of partisanship that favors player $A$ provides $A$ with a head-start advantage of $\Delta$ in terms of votes (i.e. regardless of the strategy profile $\left(\sigma_{A}, \sigma_{B}\right)$ player $A$ 's minimal vote share is at least $\left.\Delta \in[0,1 / 2)\right)$, partisanship, ultimately, provides player $A$ with an effectiveness advantage in the budget distribution component of the majoritarian game of $\gamma=(1-2 \Delta) /(1-\Delta)$.

Note that the presence of partisanship leads to the introduction of a mass point at zero in the budget distribution $F_{B}^{*}$ of the disadvantaged player, $B$, but not in the budget distribution $F_{A}^{*}$ of the advantaged player, $A$. The interpretation of player $B$ 's mass point at zero (of size $F_{B}^{*}(0)$ ) is that player $B$, the disadvantaged player, stays out of the competition with probability $F_{B}^{*}(0)$ but with probability $1-F_{B}^{*}(0)$ enters the competition and for each budget level $b$ uses the corresponding effort distribution $G_{B}^{*}(x \mid b)$, which for each budget level $b$ allocates a strictly positive level of campaign effort to each voter. That is, the disadvantaged candidate chooses, in equilibrium, to fight for the vote of each voter, i.e. $G_{B}^{*}(0 \mid b)=0$. However, for each budget level $b$ the advantaged player's, $A$ 's, effort distribution $G_{A}^{*}(x \mid b)$ features a mass point at zero. That is, player $A$, knowing that with probability $\Delta$ an arbitrary voter is loyal to $A$, chooses, in equilibrium, to rely on his advantage and allocate zero effort to a stochastic subset of the electorate of size $G_{A}^{*}(0 \mid b)>0$ for budget level $b$, which, thereby, allows the advantaged candidate to more aggressively target the remaining subset of the electorate with a higher level of expected effort per voter.

Now, we consider the case of a partisan electorate and vote-share maximizing competition. Player $A$ 's payoff in the vote-share maximizing game with endogenous budgets, partisan voters, and coarse information is given by

$$
\pi_{A}^{V S C}\left(G_{A}, G_{B}\right)=\Delta+(1-\Delta) \operatorname{Pr}\left[X_{A}>X_{B}\right]+\frac{1-\Delta}{2} \operatorname{Pr}\left[X_{A}=X_{B}\right]-E_{G_{A}}(x),
$$


and player $B$ 's payoff is given by

$$
\pi_{B}^{V S C}\left(G_{B}, G_{A}\right)=(1-\Delta) \operatorname{Pr}\left[X_{B}>X_{A}\right]+\frac{1-\Delta}{2} \operatorname{Pr}\left[X_{A}=X_{B}\right]-E_{G_{B}}(x) .
$$

From equations (29) and (30) and Theorem 2, it, again, follows from lines drawn by Hart (2016), that this game is strategically equivalent to a symmetric two-player all-pay auction with complete information in which each player has a value of $1-\Delta$ for winning the auction. The consideration of a finite set of $n$ voters is instructive again. If a share of $\Delta$ of them are loyal, the sum of independent prizes consists of the remaining $1-\Delta$ voters. As opposed to the discouragement effect arising in the majoritarian objective game, the presence of a loyalty advantage for player $A$ lowers the players' valuations of the swing voter segment (as there are fewer).

Corollary 3 In the unique Nash equilibrium $\left(\sigma_{A}^{*}, \sigma_{B}^{*}\right)$ of the vote-share maximizing game with endogenous budgets, partisan voters, and coarse information, each player $i$ 's budget distribution, $F_{i}^{*}(b)$, is degenerate with all mass placed on $b=(1-\Delta) / 2$ and each player $i$ 's effort distribution is $G_{i}^{*}(x)=x /(1-\Delta)$ for $x \in[0,1-\Delta]$. Expected payoffs in equilibrium are $\pi_{A}=\Delta$ and $\pi_{B}=0$.

Note that the equilibrium campaign budget for each candidate is $(1-\Delta) / 2$. In comparing this with the equilibrium expected campaign budget under the majoritarian objective, given by $(1-2 \Delta) / 2$, we see that for all $\Delta \in\left[0, \frac{1}{2}\right)$ campaign spending is higher under voteshare maximizing competition than under majoritarian.

\subsection{Perfect information of voter loyalty}

We, now, examine the case of perfect information in which both candidates are able to perfectly identify voters by type, and, thereby, partition loyal voters and swing voters into two identifiable segments of voters. Candidates choose segment-specific distributions of persuasive effort, denoted $G_{i}^{I}$ for player $i$ 's effort distribution for the swing, or independent, voter segment and $G_{i}^{L}$ for $i$ 's effort distribution for the loyal voter segment, and let $X_{i}^{k}$ denote the corresponding random variable for candidate $i$ in segment $k \in\{I, L\}$. Within each segment $k$ of voters, each voter receives effort as an independent draw from each candidate $i$ 's effort distribution $G_{i}^{k}$. Thus, a pure-strategy for player $i$ is a pair of effort distributions $\left\{G_{i}^{k}\right\}_{k=I, L}$. A mixed strategy in this game is a bivariate probability distribution $\sigma_{i} \in \Sigma^{2}$ over the set of pure strategies $S$ for loyal voters and the set of pure strategies $S$ for swing voters, where $\sigma_{i}^{k} \in \Sigma, k \in\{I, L\}$, denotes the marginal distribution function of $\sigma_{i}$ that specifies player $i$ 's randomization over the set of pure strategies $S$ for voter segment $k$. For each $k \in\{I, L\}$, let $\eta_{i}^{k}\left(b_{k} \mid \sigma_{i}^{k}\right)=\left\{G_{i}^{k} \in \operatorname{Supp}\left(\sigma_{i}^{k}\right) \mid E_{G_{i}}(x)=b_{k}\right\}$ denote the set of pure strategies in the support of $\sigma_{i}^{k}$ that have the same expected cost 
$b_{k}$. We define player $i$ 's budget distribution function $F_{i}(b)$ as the probability that for the random effort distributions $\widetilde{G}_{i}^{L}$ and $\widetilde{G}_{i}^{I}$ drawn from the mixed strategy $\sigma_{i}$ the sum of the mean $2^{25} E_{\widetilde{G}_{i}^{L}}(x)+E_{\widetilde{G}_{i}^{I}}(x)$ is less than or equal to $b$. Player $i$ 's payoff in the majoritarian game with endogenous budgets and perfect information regarding voter loyalty is given by

$$
\pi_{i}^{M P}\left(\left\{G_{i}^{k}\right\}_{k=I, L},\left\{G_{-i}^{k}\right\}_{k=I, L}\right)=w_{i}^{P}\left(G_{i}^{I}, G_{-i}^{I}\right)-\Delta E_{G_{i}^{L}}(x)-(1-\Delta) E_{G_{i}^{I}}(x) .
$$

The key difference in moving from coarse to perfect information, as can been in seen comparing equations (14) and (31), is that with perfect information the players have the ability to more efficiently target their campaign spending, thereby lowering the effective cost of campaign spending.

Proposition 3 In any Nash equilibrium $\left(\sigma_{A}^{*}, \sigma_{B}^{*}\right)$ of the majoritarian game with endogenous budgets, partisan voters, and perfect information each player $i$ 's effort distribution for the loyal voters $G_{i}^{L *}(x)$ is degenerate with all mass placed at 0 . Player $A$ 's budget distribution is

$$
F_{A}^{*}(b)=\left\{\begin{array}{ccc}
\frac{b}{\frac{1-2 \Delta}{(1-\Delta)^{2}}} & \text { for } & b \in\left[0, \frac{1-2 \Delta}{(1-\Delta)^{2}}\right) \\
1 & \text { for } & b \geq \frac{1-2 \Delta}{(1-\Delta)^{2}}
\end{array},\right.
$$

and player A's family of offer distributions for the swing voter segment is, for almost every $b \in[0,1-2 \Delta / 1-\Delta], \eta_{A}^{*}\left(b \mid \sigma_{A}^{*}\right)=\left\{G_{A}^{I *}(x \mid b)\right\}$ where

$$
G_{A}^{I *}(x \mid b)=\left\{\begin{array}{ccc}
1-\frac{1-2 \Delta}{1-\Delta}+\frac{1-2 \Delta}{1-\Delta} \frac{x}{2 b \frac{1-\Delta}{1-2 \Delta}} & \text { for } & x \in\left[0,2 b \frac{1-\Delta}{1-2 \Delta}\right] \\
1 & \text { for } & x>2 b \frac{1-\Delta}{1-2 \Delta}
\end{array},\right.
$$

Similarly, player B's budget distribution is

$$
F_{B}^{*}(b)=\left\{\begin{array}{ccc}
1-\frac{1-2 \Delta}{1-\Delta}+\frac{b}{\frac{1}{1-2 \Delta}} & \text { for } & b \in\left[0, \frac{1}{1-\Delta}\right) \\
1 & \text { for } & b \geq \frac{1}{1-\Delta}
\end{array}\right.
$$

and player $B$ 's family of offer distributions for the swing voter segment is, for almost every $b \in[0,1], \eta_{B}^{*}\left(b \mid \sigma_{B}^{*}\right)=\left\{G_{B}^{I *}(x \mid b)\right\}$ where

$$
G_{B}^{I *}(x \mid b)=\left\{\begin{array}{rcc}
\frac{x}{2 b} & \text { for } & y \in[0,2 b] \\
1 & \text { for } & x>2 b
\end{array} .\right.
$$

Expected campaign budgets are the same for the two candidates and given by

$$
\frac{1-2 \Delta}{2(1-\Delta)}
$$

\footnotetext{
${ }^{25}$ Note that that to calculate the expected cost the means must be weighted by the mass of the voter segment that they are targeted to, as in equation (31).
} 
Expected payoffs in equilibrium are

$$
\pi_{A}=\frac{\Delta}{(1-\Delta)^{2}} \text { and } \pi_{B}=0 .
$$

The proof of Proposition 3 relies on the same forces as the proof of Proposition 2. For the budget distribution component of the problem, note that perfect information's increased targeting efficiency/lower effective costs of voter-specific campaign spending in equation (31) are equivalent to lowering the costs of campaign spending from 1 to $1-\Delta$. Furthermore, the equilibrium budget distributions, $F_{A}^{*}$ and $F_{B}^{*}$, in Proposition 2 correspond to the unique equilibrium of an unfair all-pay auction in which each player has a value of $V=1 /(1-\Delta)$ for winning the object ${ }^{26}$ and player $A$ has an effectiveness advantage of $\gamma=(1-2 \Delta) /(1-\Delta)$. Because nothing has changed in the effort distribution component of the problem, Fact 2 applies with the caveat that $E_{G_{B}}(x) \leq 1$ is replaced by $E_{G_{B}}(x) \leq 1 /(1-\Delta)$ and $E_{G_{A}}(x) \leq(1-2 \Delta) /(1-\Delta)$ is replaced by $E_{G_{A}}(x) \leq(1-2 \Delta) /(1-\Delta)^{2}$.

Finally, consider the case of a partisan electorate and vote-share maximizing competition with perfect information. Player $A$ 's payoff is given by

$$
\begin{array}{r}
\pi_{A}^{V S P}\left(\left\{G_{A}^{k}\right\}_{k=I, L},\left\{G_{B}^{k}\right\}_{k=I, L}\right)=\Delta+(1-\Delta) \operatorname{Pr}\left[X_{A}^{I}>X_{B}^{I}\right]+\frac{1-\Delta}{2} \operatorname{Pr}\left[X_{A}^{I}=X_{B}^{I}\right] \\
-\Delta E_{G_{A}^{L}}(x)-(1-\Delta) E_{G_{A}^{I}}(x),
\end{array}
$$

and player $B$ 's payoff is given by

$$
\begin{aligned}
& \pi_{B}^{V S P}\left(\left\{G_{B}^{k}\right\}_{k=I, L},\left\{G_{A}^{k}\right\}_{k=I, L}\right)=(1-\Delta) \operatorname{Pr}\left[X_{B}^{I}>X_{A}^{I}\right]+\frac{1-\Delta}{2} \operatorname{Pr}\left[X_{A}^{I}=X_{B}^{I}\right] \\
& -\Delta E_{G_{B}^{L}}(x)-(1-\Delta) E_{G_{B}^{I}}(x) \text {. }
\end{aligned}
$$

From equations (38) and (39) and Theorem 2, it, again, follows from lines drawn by Hart (2016), that this game is strategically equivalent to a symmetric two-player all-pay auction with complete information in which each player has a value of 1 for winning the auction. Here again, we see that the presence of a loyalty advantage for player $A$ lowers the players' valuations of the swing voter segment which has decreased in size from a measure of 1 to a measure of $1-\Delta$.

Corollary 4 In the unique Nash equilibrium $\left(\sigma_{A}^{*}, \sigma_{B}^{*}\right)$ of the vote-share maximizing game with endogenous budgets, partisan voters, and perfect information, each player $i$ 's budget distribution, $F_{i}^{*}(b)$, is degenerate with all mass placed on $b=1 / 2$, each player $i$ 's effort

\footnotetext{
${ }^{26}$ Note that in the unfair all-pay auction defined above each player has a constant marginal cost of effort of 1 . In the case of voter loyalty, the independent voters make up $1-\Delta$ of the electorate, and an average effort of 1 for the indpendent voters implies a total cost of effort of $1-\Delta$. To map this game into the unfair all-pay auction, it is necessary to normalize the cost of effort to 1.
} 
distribution for the loyal voters, $G_{i}^{L *}(x)$ is degenerate with all mass placed at 0 and each player $i$ 's effort distribution for the swing voters is $G_{i}^{I *}(x)=x$ for $x \in[0,1]$. Expected payoffs in equilibrium are $\pi_{A}=\Delta$ and $\pi_{B}=0$.

\subsection{Comparison of Equilibria Across Electoral Systems and In- formation Levels}

The following table provides the equilibrium expected expenditures and payoffs for each of the four possible combinations of an electoral system, majoritarian or proportional, and an information level, coarse or perfect. The last column, from the left, in Table 1 provides the equilibrium expected expenditures and payoffs for both the majoritarian and proportional systems when there is no voter loyalty $(\Delta=0)$.

\begin{tabular}{|l||c|c|c|c|c|}
\hline & Maj. Coarse & Prop. Coarse & Maj. Perf. & Prop. Perf. & No Loyalty \\
\hline \hline Budget & $\frac{1-2 \Delta}{2(1-\Delta)}$ & $\frac{1-\Delta}{2}$ & $\frac{1-2 \Delta}{2(1-\Delta)}$ & $\frac{1-\Delta}{2}$ & $\frac{1}{2}$ \\
\hline Payoffs & $\frac{\Delta}{1-\Delta}, 0$ & $\Delta, 0$ & $\frac{\Delta}{(1-\Delta)^{2}}, 0$ & $\Delta, 0$ & 0,0 \\
\hline
\end{tabular}

Table 1: Equilibrium Expected Budgets and Payoffs

From Table 1, we see that holding constant the electoral system, the level of information has no effect on the equilibrium expected budget. Equilibrium expected expenditures are higher in the proportional system than in the majoritarian system. The advantaged player's, A's, equilibrium expected payoffs are ranked from highest to lowest as follows: majoritarian with perfect information, majoritarian with coarse information, and then the two proportional systems. This follows from the fact that the majoritarian system generates a larger discouragement effect for the disadvantaged player, $B$ and that with perfect information the advantaged candidate is able to more efficiently exploit his voter loyalty advantage.

The level-playing field effect - i.e. equilibrium expenditures increase as the playing field becomes more level and the contest becomes more competitive - is common in allpay contests. For example, in the unfair all-pay auction examined above the equilibrium expenditures are $\gamma \mathrm{V} / 2$ which are increasing as the size of player $A$ 's effectiveness of bids advantage decreases, i.e. $\gamma \rightarrow 127$ Intuitively, the vote-share maximizing game's lack of a discontinuity (at a majority of voters) in the benefit part of each player's payoff function is less discouraging for the disadvantaged player, $B$. Thus, $A$ 's loyalty advantage has less of a discouragement effect under vote-share maximizing competition.

\footnotetext{
${ }^{27}$ See also Che and Gale (1998) and Baye, Kovenock, and de Vries (1993) who examine this issue in the context of political lobbying.
} 
Switching from coarse to perfect information about loyalty allows candidates to target their persuasive efforts to only the swing voters. If the loyalty status of a voter can be observed by the candidates, only swing voters are targeted with effort in equilibrium, and the expected attention given to each swing voter is higher with perfect information. ${ }^{28}$ In terms of the potential role of campaign finance reforms and regulation of information gathering by political parties, one implication of privacy of information about loyalty is that it makes campaign spending more inclusive in the sense that all voters can expect to get positive attention from the two candidates without affecting the expected total budget or winning probabilities 29

\section{Concluding remarks}

In this paper, we characterized Nash equilibrium in a game that is of increasing practical importance: simultaneous persuasive campaigning in majoritarian electoral systems with voter-specific campaign spending. We focused on campaign expenditures that target voters and are of an all-pay nature: expenditures are made prior to the election and cannot be recovered by a candidate, whether or not he wins. The candidates compete in either a majoritarian election or a proportional election and simultaneously choose how much to spend and how to allocate their expenditure among the voters. We also allow for a partisan electorate with a segment of "loyal" voters who vote for a particular candidate regardless of the voter-specific campaign spending that they receive, and compare the outcomes across regimes with either the majoritarian or proportional objectives and with either coarse or perfect information.

From a structural/theoretical point of view, two seminal contributions are nested in this model. One is Myerson's (1993) model of two-candidate (re)distributive political competition that is based on a variation of the Colonel Blotto game. The other is the standard all-pay auction in which each player chooses a level of sunk effort. Both problems have been studied in detail, allowing for many departures from various aspects of

\footnotetext{
${ }^{28}$ This 'swing voter' outcome commonly arises in models of redistributive competition. For example this arises in classic models of redistributive politics with imperfect targeting such as Cox and McCubbins (1986), Lindbeck and Weibull (1987), and, when parties are equally effective in targeting resources across voter segments, Dixit and Londregan (1996). See also the more closely related literature in which voters may be perfectly sorted into segments by their level of attachment to a party and the parties may target resources to each identifiable segment, such as Kovenock and Roberson (2008, 2009). For a recent survey of empirical work that exmines these, and related, issues in (re)distributive politics, see Golden and Min (2013).

${ }^{29}$ It is interesting to notice that Schipper and Woo (2014) obtain that micro-targeting based on complete information about voters' preferences yields desirable implications for the electoral outcomes in a very different setup.
} 
symmetry. We characterize equilibrium in a model that combines aspects of both problems, and elements of the solutions of each of these two frameworks show up in our equilibrium. We find that homogenous voters receive different amounts of attention in the equilibrium. We also find that the equilibrium budget distributions coincide with the equilibrium distributions of bids in the standard all-pay auction, and full dissipation of rents occurs in the case of symmetric candidates. A further finding is that supermajorities are likely to occur under majority rule but not in a proportional system. This provides a new hypothesis for this phenomenon.

\section{Appendix}

\section{Proof of Theorem 2}

This Appendix contains the characterization of the unique equilibrium budget distribution and the unique parametric family of effort distributions, for each player $i \in\{A, B\}$. The proof consists of two parts. First, we establish that in all equilibria each player $i$ has the same unique budget distribution, denoted by $F_{i}(b)$. This portion of the proof consists of Lemmas 1-7. Next, we show that in all equilibria each player $i$ has a unique effort distribution $G_{i}(x \mid b)$ for each budget level $b \in \operatorname{Supp}\left(F_{i}\right)$. This portion of the proof consists of Lemmas 8-13.

Beginning with Lemmas 1 and 2, Lemma 1 establishes that each player $i$ 's mixed strategy $\sigma_{i}$ satisfies the property that if there exists a pair $G_{i}, G_{i}^{\prime} \in S u p p\left(\sigma_{i}\right)$ such that $E_{G_{i}}(x)=E_{G_{i}^{\prime}}(x)$, then it must almost surely 30 be the case that $E_{\sigma_{-i}}\left(w_{i}\left(G_{i}, G_{-i}\right)\right)=E_{\sigma_{-i}}\left(w_{i}\left(G_{i}^{\prime}, G_{-i}\right)\right)$. Recall that $\eta_{i}\left(b_{i} \mid \sigma_{i}\right)=\left\{G_{i} \in \operatorname{Supp}\left(\sigma_{i}\right) \mid E_{G_{i}}(x)=b_{i}\right\}$ denotes the set of pure strategies in the support of $\sigma_{i}$ that have the same expected cost $b_{i}$.

Lemma 1 In any equilibrium $\left(\sigma_{A}, \sigma_{B}\right)$, there exist constants $k_{b_{i}} \geq 0$, one for each $b_{i}$ such that $\eta_{i}\left(b_{i} \mid \sigma_{i}\right) \neq \emptyset$, such that if $G_{i} \in \eta_{i}\left(b_{i} \mid \sigma_{i}\right)$ then $E_{\sigma_{-i}}\left(w_{i}\left(G_{i}, G_{-i}\right)\right)=k_{b_{i}}$ almost surely.

Lemma 1, which implies that all effort distributions with the same expenditure win the contest with the same probability, follows directly from the fact that in equilibrium no player $i$ has a payoff increasing deviation. Let $\bar{b}_{i}$ and $\underline{b}_{i}$ denote the upper and lower bounds, respectively of the support of player $i$ 's budget distribution $\left(F_{i}\right)$.

Let $\widehat{w}_{i}\left(G_{i}, G_{-i}\right)$ be defined as follows

$$
\widehat{w}_{i}\left(G_{i}, G_{-i}\right)= \begin{cases}1 & \text { if } E_{G_{i}}(x)>E_{G_{-i}}(x), \\ \frac{1}{2} & \text { if } E_{G_{i}}(x)=E_{G_{-i}}(x), \\ 0 & \text { if } E_{G_{i}}(x)<E_{G_{-i}}(x) .\end{cases}
$$

\footnotetext{
${ }^{30}$ Because the support of a distribution function is the complement of the union of all open sets of $S$ with $\sigma_{i}$-volume 0 , it is possible that there may exist points $G_{i} \in \operatorname{Supp}\left(\sigma_{i}\right)$ where $G_{i}$ yields less than the equilibrium payoffs. However, such points must occur with probability zero.
} 
Lemma 2 establishes that if $\left(\sigma_{1}, \sigma_{2}\right)$ is an equilibrium, then it must be the case that for almost every $G_{i} \in \operatorname{Supp}\left(\sigma_{i}\right), E_{\sigma_{-i}}\left(w_{i}\left(G_{i}, G_{-i}\right)\right)=E_{\sigma_{-i}}\left(\widehat{w}_{i}\left(G_{i}, G_{-i}\right)\right)$, where - in the absence of a tie occurring at $E_{G_{i}}(x)$ with a strictly positive probability $-E_{\sigma_{-i}}\left(\widehat{w}_{i}\left(G_{i}, G_{-i}\right)\right)=F_{-i}\left(E_{G_{i}}(x)\right)$.

Lemma 2 In any equilibrium $\left(\sigma_{A}, \sigma_{B}\right)$, it must almost surely be the case that for $G_{i} \in \operatorname{Supp}\left(\sigma_{i}\right)$, $E_{\sigma_{-i}}\left(w_{i}\left(G_{i}, G_{-i}\right)\right)=E_{\sigma_{-i}}\left(\widehat{w}_{i}\left(G_{i}, G_{-i}\right)\right)$.

Proof There are two parts of the proof. First, we show that for $G_{i} \in \operatorname{Supp}\left(\sigma_{i}\right), E_{\sigma_{-i}}\left(w_{i}\left(G_{i}, G_{-i}\right)\right) \geq$ $E_{\sigma_{-i}}\left(\widehat{w}_{i}\left(G_{i}, G_{-i}\right)\right)$ almost surely. Then, we show that for $G_{i} \in \operatorname{Supp}\left(\sigma_{i}\right), E_{\sigma_{-i}}\left(w_{i}\left(G_{i}, G_{-i}\right)\right) \leq$ $E_{\sigma_{-i}}\left(\widehat{w}_{i}\left(G_{i}, G_{-i}\right)\right)$ almost surely. The combination of these two parts yields the desired result.

Beginning with part 1 and by way of contradiction, suppose that there exists an equilibrium in which for a player $i$ and a set $\mathcal{G}_{i} \subset \operatorname{Supp}\left(\sigma_{i}\right)$ occurring with strictly positive probability under $\sigma_{i}$ it is the case that $E_{\sigma_{-i}}\left(w_{i}\left(G_{i}, G_{-i}\right)\right)<E_{\sigma_{-i}}\left(\widehat{w}_{i}\left(G_{i}, G_{-i}\right)\right)$ for all $G_{i} \in \mathcal{G}_{i}$. A feasible deviation for player $i$ is to hold $F_{i}(b)$, and thus expected costs, constant, but at each $G_{i} \in \mathcal{G}_{i}$ to deviate to the effort distribution $G_{i}(x)=x / 2 b$ for $x \in[0,2 b]$, where $b=E_{G_{i}}(x)$. Under this expected-cost invariant deviation, player $i$ ensures that $E_{\sigma_{-i}}\left(w_{i}\left(G_{i}, G_{-i}\right)\right)=E_{\sigma_{-i}}\left(\widehat{w}_{i}\left(G_{i}, G_{-i}\right)\right)$. This is clearly a payoff increasing deviation, which creates a contradiction to the assumption that there exists an equilibrium in which for a player $i$ and a set $\mathcal{G}_{i} \subset \operatorname{Supp}\left(\sigma_{i}\right)$ occurring with strictly positive probability it is the case that $E_{\sigma_{-i}}\left(w_{i}\left(G_{i}, G_{-i}\right)\right)<E_{\sigma_{-i}}\left(\widehat{w}_{i}\left(G_{i}, G_{-i}\right)\right)$ for all $G_{i} \in \mathcal{G}_{i}$. This concludes the proof of part 1 .

Moving on to part 2 and by way of contradiction, suppose that there exists an equilibrium in which for a player $i$ and a set $\mathcal{G}_{i} \subset \operatorname{Supp}\left(\sigma_{i}\right)$ occurring with strictly positive probability under $\sigma_{i}$ it is the case that $E_{\sigma_{-i}}\left(w_{i}\left(G_{i}, G_{-i}\right)\right)>E_{\sigma_{-i}}\left(\widehat{w}_{i}\left(G_{i}, G_{-i}\right)\right)$ for all $G_{i} \in \mathcal{G}_{i}$. From part 1 we know that for $G_{i} \in S u p p\left(\sigma_{i}\right), E_{\sigma_{-i}}\left(w_{i}\left(G_{i}, G_{-i}\right)\right) \geq E_{\sigma_{-i}}\left(\widehat{w}_{i}\left(G_{i}, G_{-i}\right)\right)$ almost surely. Combining this with the assumption that $E_{\sigma_{-i}}\left(w_{i}\left(G_{i}, G_{-i}\right)\right)>E_{\sigma_{-i}}\left(\widehat{w}_{i}\left(G_{i}, G_{-i}\right)\right)$ for all $G_{i} \in \mathcal{G}_{i}$, it follows that $E_{\sigma_{i}}\left(E_{\sigma_{-i}}\left(w_{i}\left(G_{i}, G_{-i}\right)\right)\right)>E_{\sigma_{i}}\left(E_{\sigma_{-i}}\left(\widehat{w}_{i}\left(G_{i}, G_{-i}\right)\right)\right)$ for player $i$. Next, note that $E_{\sigma_{i}}\left(E_{\sigma_{-i}}\left(w_{i}\left(G_{i}, G_{-i}\right)\right)\right)+E_{\sigma_{-i}}\left(E_{\sigma_{i}}\left(w_{-i}\left(G_{-i}, G_{i}\right)\right)\right)=1$ and thus,

$$
E_{\sigma_{-i}}\left(E_{\sigma_{i}}\left(w_{-i}\left(G_{-i}, G_{i}\right)\right)\right)=1-E_{\sigma_{i}}\left(E_{\sigma_{-i}}\left(w_{i}\left(G_{i}, G_{-i}\right)\right)\right)<1-E_{\sigma_{i}}\left(E_{\sigma_{-i}}\left(\widehat{w}_{i}\left(G_{i}, G_{-i}\right)\right)\right) .
$$

Noting that $E_{\sigma_{i}}\left(E_{\sigma_{-i}}\left(\widehat{w}_{i}\left(G_{i}, G_{-i}\right)\right)\right)+E_{\sigma_{-i}}\left(E_{\sigma_{i}}\left(\widehat{w}_{-i}\left(G_{-i}, G_{i}\right)\right)\right)=1$ it follows that equation 40 may be written as

$$
E_{\sigma_{-i}}\left(E_{\sigma_{i}}\left(w_{-i}\left(G_{-i}, G_{i}\right)\right)\right)<E_{\sigma_{-i}}\left(E_{\sigma_{i}}\left(\widehat{w}_{-i}\left(G_{-i}, G_{i}\right)\right)\right) .
$$

Because part 1 implies that $E_{\sigma_{i}}\left(E_{\sigma_{-i}}\left(w_{i}\left(G_{i}, G_{-i}\right)\right)\right) \geq E_{\sigma_{i}}\left(E_{\sigma_{-i}}\left(\widehat{w}_{i}\left(G_{i}, G_{-i}\right)\right)\right)$ for each player $i$, equation (41) yields a contradiction to the assumption that there exists an equilibrium in which for a player $i$ and a set $\mathcal{G}_{i} \subset S u p p\left(\sigma_{i}\right)$ occurring with strictly positive probability it is the case that $E_{\sigma_{-i}}\left(w_{i}\left(G_{i}, G_{-i}\right)\right)>E_{\sigma_{-i}}\left(\widehat{w}_{i}\left(G_{i}, G_{-i}\right)\right)$ for all $G_{i} \in \mathcal{G}_{i}$.

It follows from part $1-$ for $G_{i} \in \operatorname{Supp}\left(\sigma_{i}\right), E_{\sigma_{-i}}\left(w_{i}\left(G_{i}, G_{-i}\right)\right) \geq E_{\sigma_{-i}}\left(\widehat{w}_{i}\left(G_{i}, G_{-i}\right)\right)$ almost surely - and part 2 - for $G_{i} \in \operatorname{Supp}\left(\sigma_{i}\right), E_{\sigma_{-i}}\left(w_{i}\left(G_{i}, G_{-i}\right)\right) \leq E_{\sigma_{-i}}\left(\widehat{w}_{i}\left(G_{i}, G_{-i}\right)\right)$ almost surely - that it must almost surely be the case that for $G_{i} \in S u p p\left(\sigma_{i}\right), E_{\sigma_{-i}}\left(w_{i}\left(G_{i}, G_{-i}\right)\right)=$ $E_{\sigma_{-i}}\left(\widehat{w}_{i}\left(G_{i}, G_{-i}\right)\right)$. This concludes the proof of Lemma 2 . 
It follows from Lemma 2 that if $\left(\sigma_{A}, \sigma_{B}\right)$ is an equilibrium, then player $i$ 's expected payoff from any pure strategy $G_{i} \in \operatorname{Supp}\left(\sigma_{i}\right)$ with expected cost $E_{G_{i}}(x)$ may be written as

$$
E_{\sigma_{-i}}\left(\widehat{w}_{i}\left(G_{i}, G_{-i}\right)\right)-E_{G_{i}}(x) .
$$

Note that in the absence of a tie occurring with a strictly positive probability in the equilibrium $\left(\sigma_{1}, \sigma_{2}\right), E_{\sigma_{-i}}\left(\widehat{w}_{i}\left(G_{i}, G_{-i}\right)\right)=F_{-i}\left(E_{G_{i}}(x)\right)$ for $G_{i} \in \operatorname{Supp}\left(\sigma_{i}\right)$.

The proofs of Lemmas 3-6 follow from equation (42) and standard arguments from the proof of uniqueness for the two-player all-pay auction. Together with equation (42), Lemmas 3-6 establish the uniqueness of the equilibrium budget distribution functions $\left(F_{1}, F_{2}\right)$.

Lemma 3 In any equilibrium $\left(\sigma_{A}, \sigma_{B}\right), \underline{b}_{1}=\underline{b}_{2}=0$.

Lemma 4 In any equilibrium $\left(\sigma_{A}, \sigma_{B}\right)$, (i) there is no point in the budget distribution function $F_{i}$ at which both players place strictly positive mass and (ii) neither player places strictly positive mass on any strictly positive point in the support of $F_{i}$.

Lemma 5 In any equilibrium $\left(\sigma_{A}, \sigma_{B}\right)$, each player's budget distribution function is strictly increasing over its support.

Lemma 6 In any equilibrium $\left(\sigma_{A}, \sigma_{B}\right), \bar{b}_{1}=\bar{b}_{2}=1$.

To summarize, equation (42) and Lemmas 1-6 establish that in all equilibria each player $i$ has the same unique distribution of expected costs, $F_{i}^{*}(b)=b$ for $b \in[0,1]$.

Lemma 7 In any equilibrium $\left(\sigma_{A}, \sigma_{B}\right)$, each player $i$ 's distribution of expected costs is given by $F_{i}^{*}(b)=b$ for $b \in[0,1]$.

Lemmas 8-13 examine the remaining portion of the proof, that in all equilibria each player $i$ has a unique effort distribution $G_{i}(x \mid b)$ for each level of expected costs $b \in[0,1]$, i.e. a unique parametric family of effort distributions $\left\{G_{i}(x \mid b) \mid b \in[0,1]\right\}$.

We begin with Lemma 8 which establishes that all equilibria are interchangeable with the equilibrium stated in Theorem 2. Let $E_{\sigma_{i}}(x)$ denote the expected cost of the mixed strategy $\sigma_{i}$, and note that in any equilibrium strategy $\sigma_{i}$, it follows from equation 42 and Lemma 7 that $E_{\sigma_{i}}(x)=E_{F_{i}^{*}}(x)=1 / 2$.

Lemma 8 If $\left(\sigma_{A}, \sigma_{B}\right)$ is an equilibrium, then $\left(\sigma_{A}, \sigma_{B}\right)$ is interchangeable with $\left(\sigma_{A}^{*}, \sigma_{B}^{*}\right)$.

Proof Because $\left(\sigma_{A}, \sigma_{B}\right)$ and $\left(\sigma_{A}^{*}, \sigma_{B}^{*}\right)$ are both equilibria we know that in each equilibrium neither player has a payoff increasing deviation. Hence, we have the four following inequalities:

$$
\begin{gathered}
\operatorname{Pr}\left(1 \text { wins } \mid \sigma_{1}, \sigma_{2}\right)-E_{\sigma_{1}}(x) \geq \operatorname{Pr}\left(1 \text { wins } \mid \sigma_{1}^{*}, \sigma_{2}\right)-E_{\sigma_{1}^{*}}(x), \\
\operatorname{Pr}\left(1 \text { wins } \mid \sigma_{1}^{*}, \sigma_{2}^{*}\right)-E_{\sigma_{1}^{*}}(x) \geq \operatorname{Pr}\left(1 \text { wins } \mid \sigma_{1}, \sigma_{2}^{*}\right)-E_{\sigma_{1}}(x), \\
1-\operatorname{Pr}\left(1 \text { wins } \mid \sigma_{1}, \sigma_{2}\right)-E_{\sigma_{2}}(x) \geq 1-\operatorname{Pr}\left(1 \text { wins } \mid \sigma_{1}, \sigma_{2}^{*}\right)-E_{\sigma_{2}^{*}}(x),
\end{gathered}
$$




$$
1-\operatorname{Pr}\left(1 \text { wins } \mid \sigma_{1}^{*}, \sigma_{2}^{*}\right)-E_{\sigma_{2}^{*}}(x) \geq 1-\operatorname{Pr}\left(1 \text { wins } \mid \sigma_{1}^{*}, \sigma_{2}\right)-E_{\sigma_{2}}(x) .
$$

Recall that from Lemma 7 any equilibrium strategy $\sigma_{i}$ necessarily has the unique equilibrium distribution of expected costs, $F_{i}^{*}(b)=b$ for $b \in[0,1]$. Thus, for each player $i, E_{\sigma_{i}^{*}}(x)=$ $E_{\sigma_{i}}(x)=E_{F_{i}^{*}}(x)=1 / 2$. Then, taking the sum of equations 43) to 46, we have $0 \geq 0$ which implies that (43)-(46) all hold with equality. But, if (43)-(46) all hold with equality, then this implies that $\sigma_{A}$ and $\sigma_{B}^{*}$ are best-responses to each other, and that $\sigma_{A}^{*}$ and $\sigma_{B}$ are best-responses to each other. Thus, the two equilibria $\left(\sigma_{A}, \sigma_{B}\right)$ and $\left(\sigma_{A}^{*}, \sigma_{B}^{*}\right)$ are interchangeable.

In Lemma 9 we show that if $\left(\sigma_{A}, \sigma_{B}\right)$ is an equilibrium, then from Lemma 8's result on the interchangeability of equilibria, we can use the fact that $\sigma_{B}^{*}$ is a best-response to $\sigma_{A}$ to provide a necessary condition that holds for almost every effort distribution in any equilibrium parametric family of effort distributions.

Note that because each effort distribution $G_{i}(x \mid b)$ is monotonic, each $G_{i}(x \mid b)$ is differentiable almost everywhere, where $g_{i}(x \mid b)$ denotes the derivative of $G_{i}(x \mid b)$. Note also that because $\left\{G_{i}^{*}(x \mid b) \mid b \in[0,1]\right\}$ satisfies the property that for each $b^{\prime}>b$ it is the case that $G_{i}^{*}\left(x \mid b^{\prime}\right)$ first-order stochastically dominates $G_{i}^{*}(x \mid b)$ we know that for all $b^{\prime \prime} \in(0,1]$ and $b^{\prime}>b$ that $\int G_{-i}\left(x \mid b^{\prime \prime}\right) g_{i}\left(x \mid b^{\prime}\right) d x \geq \int G_{-i}\left(x \mid b^{\prime \prime}\right) g_{i}(x \mid b) d x$. Let $\mathcal{F} \mathcal{S D}$ denote the set of parametric families of effort distributions that satisfy first-order stochastic dominance with respect to the expected cost, $b$.

Lemma 9 In any equilibrium $\left(\sigma_{A}, \sigma_{B}\right)$ and for almost every $b \in[0,1], g_{i}(x \mid b)$ is equal to a constant for almost every $x \in[0,1]$ and for each player $i$.

Proof By way of contradiction, suppose that there exists an equilibrium $\left(\sigma_{A}, \sigma_{B}\right)$ such that for at least one player $i$ there exists a measurable set of expected costs $b \in[0,1]$ such that $g_{-i}(x \mid b)$ is not equal to a constant for almost every $x \in[0,1]$. From Lemma $8,\left(\sigma_{i}^{*}, \sigma_{-i}\right)$ is also an equilibrium, and it must be the case that the parametric family of effort distributions $\left\{G_{i}^{*}(x \mid b) \mid b \in[0,1]\right\}$ is a best response to $\left\{G_{-i}(x \mid b) \mid b \in[0,1]\right\}$. If we restrict our attention to possible deviations in the set $\mathcal{F S D}$, i.e. parametric families of effort distributions that satisfy the first-order stochastic dominance property, then for almost every $b \in[0,1]$ player $i$ 's problem is

$$
\min _{G_{i}(x)} \int x g_{i}(x) d x
$$

subject to the constraint ${ }^{31}$ that $\int G_{-i}(x \mid b) g_{i}(x) d x \geq \frac{1}{2}$. The first variation provides a necessary condition for this problem, and, hence, letting $\lambda \geq 0$ denote the multiplier on the constraint, it must be the case that $G_{-i}(x \mid b)$ satisfies the condition that

$$
1-\lambda g_{-i}(x \mid b)=0
$$

for almost every $x \in[0,1]$ such that $g_{i}(x)>0$. Because, $g_{i}^{*}(x \mid b)>0$ for all $x \in[0,1]$ and $G_{i}^{*}(x \mid b)$ is a solution to this problem, equation (47) is a contradiction to the assumption that

\footnotetext{
${ }^{31}$ Note that because $\int G_{-i}(x \mid b) g_{i}(x \mid b) d x \geq \frac{1}{2}$ and $\left\{G_{i}(x \mid b) \mid b \in[0,1]\right\} \in \mathcal{F S D}$ it follows that $\int G_{-i}(x \mid b) g_{i}\left(x \mid b^{\prime}\right) d x>\frac{1}{2}$ for all $b^{\prime}>b$.
} 
there exists an equilibrium $\left(\sigma_{A}, \sigma_{B}\right)$ such that for at least one player $i$ there exists a measurable set of expected costs in $[0,1]$ such that $g_{-i}(x \mid b)$ is not equal to a constant. This completes the proof of Lemma 9.

Lemmas 10-12, which establish properties of the equilibrium effort distributions that parallel Lemmas 3, 4, and 6 for the equilibrium budget distributions, follow from an argument along the lines of the proof of Lemma 9, again featuring Lemma 8's interchangeability of equilibria. Let $\bar{x}_{i}\left(b_{i}\right)$ and $\underline{x}_{i}\left(b_{i}\right)$ denote the upper and lower bounds, respectively of the support of player $i$ 's effort distribution for a budget of $b_{i}$, denoted $G_{i}\left(x \mid b_{i}\right)$.

Lemma 10 In any equilibrium $\left(\sigma_{A}, \sigma_{B}\right)$ and for almost every $b_{i} \in[0,1], \underline{x}_{i}\left(b_{i}\right)=0$.

Lemma 11 In any equilibrium $\left(\sigma_{A}, \sigma_{B}\right)$ and for almost every $b_{i} \in[0,1]$, (i) there is no point in the effort distribution function $G_{i}\left(x \mid b_{i}\right)$ at which both players place strictly positive mass and (ii) neither player places strictly positive mass on any strictly positive point in the support of $G_{i}\left(x \mid b_{i}\right)$.

Lemma 12 In any equilibrium $\left(\sigma_{A}, \sigma_{B}\right)$ and for almost every $b_{i} \in[0,1], \bar{x}_{i}\left(b_{i}\right)=2 b_{i}$.

To summarize, Lemmas 8-12 together with budget balance establish that in all equilibria each player has the unique parametric family of effort distributions identified in Theorem 2.

Lemma 13 If $\left(\sigma_{A}, \sigma_{B}\right)$ is an equilibrium, then each player $i$ 's parametric family of effort distributions $\left\{G_{i}(x \mid b) \mid b \in[0,1]\right\}$ arising in $\sigma_{i}$ coincide, almost everywhere, with Theorem Q 2 's unique parametric family of equilibrium effort distributions $\left\{G_{i}^{*}(x \mid b) \mid b \in[0,1]\right\}$.

\section{Proof of Proposition 1}

We use the equilibrium strategy $\left(\sigma_{i}^{*}, \sigma_{-i}^{*}\right)$ from Theorem 2 to calculate the share of voters who vote for $i$. For $G_{i}^{*}(x \mid b)$ and $G_{-i}^{*}\left(x \mid b^{\prime}\right)$, for given $\left(b, b^{\prime}\right)$ the electoral vote share voting for $i$ is

$$
\beta_{i}\left(b, b^{\prime}\right)=\left\{\begin{array}{cll}
\operatorname{Pr}\left[X_{i}>X_{-i}\right]=\frac{b}{2 b^{\prime}} & \text { for } & b<b^{\prime}, \\
\operatorname{Pr}\left[X_{i}>X_{-i}\right]=\frac{1}{2} & \text { for } & b=b^{\prime} \\
\operatorname{Pr}\left[X_{i}>X_{-i}\right]=1-\frac{b^{\prime}}{2 b} & \text { for } & b>b^{\prime}
\end{array}\right.
$$

and analogously for $\beta_{-i}\left(b, b^{\prime}\right)$. Conditional on $b>b^{\prime}$, the probability that the vote share $\beta_{i}$ exceeds some given threshold $\bar{\beta} \in\left(\frac{1}{2}, 1\right)$ is equal to the probability that $1-\frac{b^{\prime}}{2 b}>\bar{\beta}$, or, equivalently,

$$
b>\frac{b^{\prime}}{2(1-\bar{\beta})} .
$$

Using $F_{i}^{*}(b)=b$, this implies that

$$
\operatorname{Pr}\left[\max \left\{\beta_{i}\left(b, b^{\prime}\right), \beta_{-i}\left(b, b^{\prime}\right)\right\} \geq \bar{\beta}\right]=2-2 \bar{\beta}
$$




\section{Proof of Proposition 2}

We now extend the Theorem 2 characterization of equilibrium to the majoritarian game with endogenous budgets, partisan voters, and coarse information. As this proof follows along the same lines as Theorem 2, we only provide an outline of the changes in the proof of Theorem 2. First, recall that $w_{A}^{P}\left(G_{A}, G_{B}\right)$ denotes if player $A$ wins a majority of the votes, given that player $A$ uses the pure strategy $G_{A}$ and player $B$ uses $G_{B}$, where

$$
w_{A}^{P}\left(G_{A}, G_{B}\right)= \begin{cases}1 & \text { if } \Delta+(1-\Delta) \operatorname{Pr}\left[X_{A}>X_{B}\right]+\frac{1-\Delta}{2} \operatorname{Pr}\left[X_{A}=X_{B}\right]>\frac{1}{2}, \\ \frac{1}{2} & \text { if } \Delta+(1-\Delta) \operatorname{Pr}\left[X_{A}>X_{B}\right]+\frac{1-\Delta}{2} \operatorname{Pr}\left[X_{A}=X_{B}\right]=\frac{1}{2} \\ 0 & \text { if } \Delta+(1-\Delta) \operatorname{Pr}\left[X_{A}>X_{B}\right]+\frac{1-\Delta}{2} \operatorname{Pr}\left[X_{A}=X_{B}\right]<\frac{1}{2}\end{cases}
$$

and let $w_{B}^{P}\left(G_{B}, G_{A}\right)$ be defined as $1-w_{A}^{P}\left(G_{A}, G_{B}\right)$. Player $i$ 's payoff in the majoritarian game with endogenous budgets, partisan voters, and coarse information is given by

$$
\pi_{i}^{M C}\left(G_{i}, G_{-i}\right)=w_{i}^{P}\left(G_{i}, G_{-i}\right)-E_{G_{i}}(x) .
$$

To show that Fact 2 - player $A$ can ensure a win if $E_{G_{A}}(x)>\frac{(1-2 \Delta) E_{G_{B}}(x)}{1-\Delta}$ - applies in any equilibrium, note that if we define $\widehat{w}_{A}^{P}\left(G_{i}, G_{-i}\right)$ as

$$
\widehat{w}_{A}^{P}\left(G_{i}, G_{-i}\right)= \begin{cases}1 & \text { if } E_{G_{A}}(x)>\frac{(1-2 \Delta) E_{G_{B}}(x)}{1-\Delta}, \\ \frac{1}{2} & \text { if } E_{G_{A}}(x)=\frac{(1-2 \Delta) E_{G_{B}}(x)}{1-\Delta} \\ 0 & \text { if } E_{G_{A}}(x)<\frac{(1-2 \Delta) E_{G_{B}}(x)}{1-\Delta}\end{cases}
$$

where $\widehat{w}_{B}^{P}\left(G_{B}, G_{A}\right)$ is defined as $1-\widehat{w}_{A}^{P}\left(G_{A}, G_{B}\right)$, then, a straightforward extension of Lemma 2 establishes that if $\left(\sigma_{A}, \sigma_{B}\right)$ is an equilibrium, then it must be the case that for almost every $G_{i} \in \operatorname{Supp}\left(\sigma_{i}\right), E_{\sigma_{-i}}\left(w_{i}^{P}\left(G_{i}, G_{-i}\right)\right)=E_{\sigma_{-i}}\left(\widehat{w}_{i}^{P}\left(G_{i}, G_{-i}\right)\right)$, where $E_{\sigma_{A}}\left(\widehat{w}_{A}\left(G_{A}, G_{B}\right)\right)=$ $F_{B}\left(\frac{(1-\Delta) E_{G_{A}}(x)}{1-2 \Delta}\right)$ and $E_{\sigma_{B}}\left(\widehat{w}_{B}\left(G_{B}, G_{A}\right)\right)=F_{A}\left(\frac{(1-2 \Delta) E_{G_{B}}(x)}{1-\Delta}\right)$.

Partisanship provides player $A$ with an effectiveness advantage in the budget distribution component of each player's best-response problem. More specifically, player $A$ has an effectiveness advantage of $(1-2 \Delta) /(1-\Delta)$. Next, note that the maximum amount that player $B$ is willing to spend in the electoral competition is 1 . Given player $A$ 's effectiveness advantage, it follows that the maximum amount that player $A$ is willing to spend in the electoral competition is $((1-2 \Delta) /(1-\Delta))$. Thus, a straightforward extension of Lemma 6 establishes that $\bar{b}_{A}=(1-2 \Delta) /(1-\Delta)$ and $\bar{b}_{B}=1$. From equation 48 and Lemmas 1, 3-5, and the extensions of Lemmas 2 and 6 , Lemma 7 can be extended to show that the equilibrium budget distributions, $F_{A}^{*}$ and $F_{B}^{*}$, in Proposition 2 correspond to the unique equilibrium of an unfair all-pay auction in which each player has a value of 1 for winning the object and player $A$ has an effectiveness advantage of $(1-2 \Delta) /(1-\Delta)$.

For the effort distribution component, the proof of Proposition 2 follows along the same lines as that of Theorem 2. First, note that from the extension of Lemma 2 discussed above, it follows that in any equilibrium the point at which ties occur is $E_{G_{A}}(x)=\frac{(1-2 \Delta) E_{G_{B}}(x)}{1-\Delta}$. That is, 
in any equilibrium, if player $B$ is using an effort distribution $G_{B}(x \mid b)$, then there is a tie when player $A$ uses the effort distribution $G_{A}\left(x \mid \frac{(1-2 \Delta) b}{1-\Delta}\right)$. A straightforward extension of Lemma 12 establishes that $\bar{x}_{A}\left(\frac{(1-2 \Delta) b}{1-\Delta}\right)=\bar{x}_{B}(b)=2 b$. Then Lemmas 8-11 and the extension of Lemma 12 , together with budget balance, yield the desired result.

\section{Proof of Proposition 3}

First, both politicians focus their expenditures only on the swing voters. The reason is that the loyal voters vote for politician $A$ regardless of the campaign expenditures: any dollar spent on a loyal voter will be wasted since it has a budgetary cost without increasing the probability of winning votes for any politician. This implies that only swing voters are targeted with strictly positive expenditures.

The proof of equilibrium distributions and their implication for expected budgets, and expected payoffs follows the same steps as the proof of Proposition 2. The reasoning, however, applies to the share $1-\Delta$ of swing voters. This share is deterministic and candidates know the identity of the swing voters.

\section{References}

[1] Amir, C. (2015) Uniqueness of optimal strategies in captain lotto games. University of Jerusalem, Discussion Paper 687.

[2] Austen-Smith, D. (1987) Interest groups, campaign contributions, and probabilistic voting. Public Choice 54, 123-139.

[3] Banks, J.S. (2000) Buying supermajorities in finite legislatures. American Political Science Review 94, 677-681.

[4] Barelli, P., Govindan, S., \& Wilson, R. (2014) Competition for a majority. Econometrica 82, 271-314.

[5] Baye, M.R., Kovenock, D., \& de Vries, C.G. (1996) The all-pay auction with complete information. Economic Theory 8, 291-305.

[6] Baye, M.R., Kovenock, D., \& de Vries, C.G. (1993) Rigging the lobbying process: an application of the all-pay auction. American Economic Review 83, 289-294.

[7] Bierbrauer, F.J., \& Boyer, P.C. (2016) Efficiency, welfare, and political competition. Quarterly Journal of Economics 131, 461-518.

[8] Boyer, P.C., \& Esslinger, C. (2016) Public debt and the political economy of reforms. University of Mannheim, working paper. 
[9] Che, Y.-K., \& Gale, I. (1998) Caps on political lobbying. American Economic Review 88, 643-651.

[10] Coate, S. (2004) Political competition with campaign contributions and informative advertising. Journal of the European Economic Association 2, 772-804.

[11] Cox, G.W., \& McCubbins, M.D. (1986) Electoral politics as a redistributive game. Journal of Politics 48, 370-89

[12] Crutzen, B.S.Y., \& Sahuguet, N. (2009) Redistributive politics with distortionary taxation. Journal of Economic Theory 144, 264-279.

[13] Denter, P., \& Sisak, D. (2015) Do polls create momentum in political competition? Journal of Public Economics 130, 1-14.

[14] Dewan, T., \& Shepsle, K.A. (2011) Political economy models of elections. Annual Review of Political Science 13, 311-330.

[15] Diermeier, D., \& Myerson, R.B. (1999) Bicameralism and its consequences for the internal organization of legislatures. American Economic Review 89, 1182-1196.

[16] Dixit, A., \& Londregan, J. (1996) The determinants of success of special interests in redistributive politics. Journal of Politics 58, 1132-55

[17] Erikson, R.S., \& Palfrey, T.R. (2000) Equilibria in campaign spending games: theory and data. American Political Science Review 94, 595-609.

[18] Ewerhart, C. (2016) A "fractal" solution to the chopsticks auction. University of Zurich, working paper no. 229.

[19] Golden, M., \& Min, B. (2013) Distributive politics around the world. Annual Review in Political Science 16, 73-99.

[20] Groseclose, T., \& Snyder, J.M. (1996) Buying supermajorities. American Political Science Review 90, 303-315.

[21] Groseclose, T., \& Snyder, J.M. (2000) Vote buying, supermajorities, and flooded coalitions. American Political Science Review 94, 683-684.

[22] Gross, O.A., \& Wagner, R.A. (1950) A continuous Colonel Blotto game. RAND Corporation, Research Memorandum RM-408.

[23] Hart, S. (2008) Discrete Colonel Blotto and General Lotto games. International Journal of Game Theory 36, 441-460.

[24] Hart, S. (2016) Allocation games with caps: from Captain Lotto to all-pay auctions. International Journal of Game Theory 45, 37-61. 
[25] Hersh, E.D., \& Schaffner, B.F. (2013) Targeted campaign appeals and the value of ambiguity. Journal of Politics 75, 520-534.

[26] Herrera, H., Levine, D.K., \& Martinelli, C. (2008) Policy platforms, campaign spending and voter participation. Journal of Public Economics, 92(3), 501-513.

[27] Hillman, A.L., \& Riley, J.G. (1989) Politically contestable rents and transfers. Economics and Politics 1, 17-39.

[28] Iaryczower, M., \& Mattozzi, A. (2013) On the nature of competition in alternative electoral systems. Journal of Politics 75, 743-756.

[29] Jacobson, G.C. (2015) How do campaigns matter? Annual Review of Political Science 18, 31-47.

[30] Jamieson, K.H. (2013) Messages, micro-targeting, and new media technologies. The Forum 11, 429-435.

[31] Kallenberg, O. (1997) Foundations of Modern Probability. Springer, New York.

[32] Kenski, K., Hardy, B.W., \& Jamieson, K.H. (2010) The Obama victory: how media, money and message shaped the 2008 election. Oxford University Press, New York.

[33] Konrad, K.A. (2002) Investment in the absence of property rights; the role of incumbency advantages. European Economic Review 46, 1521-1537.

[34] Kovenock, D., \& Roberson, B. (2008) Electoral poaching and party identification. Journal of Theoretical Politics 20, 275-302.

[35] Kovenock, D., \& Roberson, B. (2009) Inefficient redistribution and inefficient redistributive politics. Public Choice 139, 263-272.

[36] Kovenock, D., \& Roberson, B. (2012) Conflicts with multiple battlefields. In Garfinkel, M.R., and Skaperdas, S. (eds.) Oxford Handbook of the Economics of Peace and Conflict. Oxford University Press, New York, 503-531.

[37] Kovenock, D., \& Roberson, B. (2015) Generalizations of the General Lotto and Colonel Blotto games. CESifo Working Paper No. 5291.

[38] Lindbeck, A. \& Weibull, J. (1987) Balanced budget redistribution and the outcome of political competition. Public Choice 52, 273-97.

[39] Lizzeri, A. (1999) Budget deficits and redistributive politics. Review of Economic Studies 66, 909-928.

[40] Lizzeri, A., \& Persico, N. (2001) The provision of public goods under alternative electoral incentives. American Economic Review 91, 225-239. 
[41] Magnani, M. (2015) Electoral competition with ideologically biased voters. Working paper.

[42] Meirowitz, A. (2008) Electoral contests, incumbency advantages, and campaign finance. Journal of Politics 70, 681-699.

[43] Myerson, R.B. (1993) Incentives to cultivate favored minorities under alternative electoral systems. American Political Science Review 87, 856-869.

[44] Parthasarathy (1967) Probability Measures on Metric Spaces. American Mathematical Society, Providence, Rhode Island.

[45] Pastine, I., \& Pastine, T. (2012) Incumbency advantage and political campaign spending limits. Journal of Public Economics 96, 20-32.

[46] Prat, A. (2002) Campaign advertising and voter welfare. Review of Economic Studies $69,9971017$.

[47] Ridout, T.N., Franz, M., Goldstein, K.M., \& Feltus, W.J. (2012) Separation by television program: understanding the targeting of political advertising in presidential elections. Political Communication 29, 1-23.

[48] Roberson, B. (2006) The Colonel Blotto game. Economic Theory 29, 1-24.

[49] Roberson, B., \& Kvasov, D. (2012) The non-constant-sum Colonel Blotto game. Economic Theory 51, 397-433.

[50] Sahuguet, N., \& Persico, N. (2006) Campaign spending regulation in a model of redistributive politics. Economic Theory 28, 95-124.

[51] Schipper, B.C., \& Woo, H.Y. (2014) Political awareness, microtargeting of voters, and negative electoral campaigning. Available at SSRN: https://ssrn.com/ abstract=2039122 or http://dx.doi .org/10.2139/ssrn.2039122.

[52] Schultz, C. (2007) Strategic campaigns and redistributive politics. Economic Journal 117, 936-963.

[53] Shubik, M. (1970) Voting, or a price system in a competitive market structure. American Political Science Review 64, 179-181.

[54] Siegel, R. (2009) All-pay contests. Econometrica 77, 71-92.

[55] Siegel, R., \& Olszewski, W. (2016) Large contests. Econometrica 84, 835-854.

[56] Skaperdas, S., \& Grofman, B. (1995) Modeling negative campaigning. American Political Science Review 89, 49-61.

[57] Snyder, J.M. (1989) Election goals and the allocation of campaign resources. Econometrica 57, 637-660. 
[58] Szentes, B., \& Rosenthal, R.W. (2003a) Three-object two-bidder simultaneous auctions: chopsticks and tetrahedra. Games and Economic Behavior 44, 114-133.

[59] Szentes, B., \& Rosenthal, R.W. (2003b) Beyond chopsticks: symmetric equilibria in majority auction games. Games and Economic Behavior 45, 278-295.

[60] Tullock, G. (1980) Efficient rent-seeking. In Buchanan, J.M., Tollison, R.D., \& Tullock, G. (eds.) Toward a Theory of the Rent-Seeking Society. Texas A\&M University Press, College Station, 97-112.

[61] Ueda, K. (1998) On the incentives to cultivate favored minorities: a note. Games and Economic Behavior 25, 132-143.

[62] Washburn, A.R. (2013) Blotto politics. Operations Research 61, 532-543. 